This item was submitted to Loughborough's Research Repository by the author.

Items in Figshare are protected by copyright, with all rights reserved, unless otherwise indicated.

\title{
Control system studies of an active anti-roll bar tilt system for railway vehicles
}

PLEASE CITE THE PUBLISHED VERSION

PUBLISHER

(C) IMechE / Professional Engineering Publishing

\section{VERSION}

VoR (Version of Record)

\section{LICENCE}

CC BY-NC-ND 4.0

\section{REPOSITORY RECORD}

Pearson, John T., Roger M. Goodall, and lan Pratt. 2019. "Control System Studies of an Active Anti-roll Bar Tilt System for Railway Vehicles". figshare. https://hdl.handle.net/2134/4519. 
This item was submitted to Loughborough's Institutional Repository (https://dspace.lboro.ac.uk/) by the author and is made available under the following Creative Commons Licence conditions.

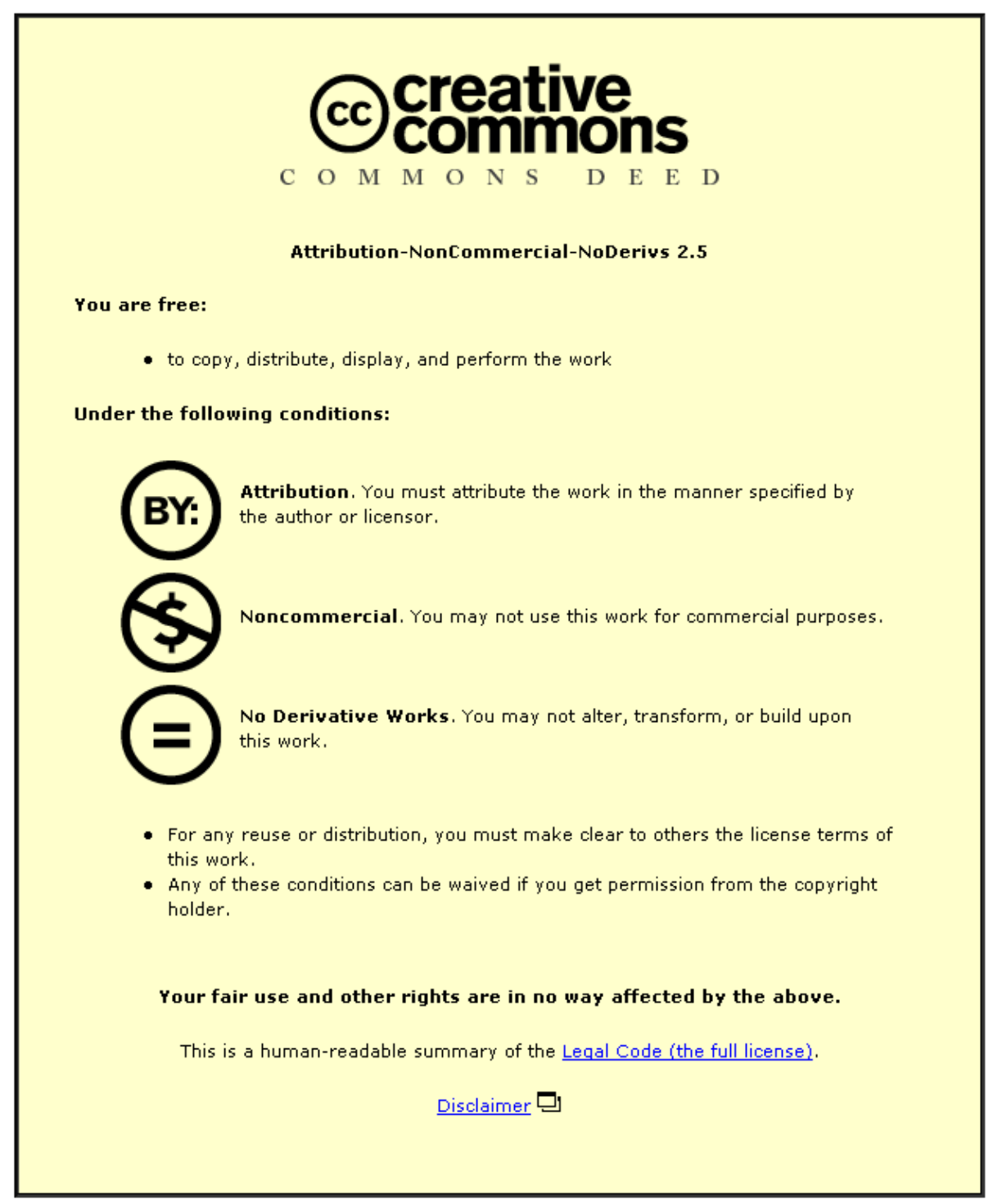

For the full text of this licence, please go to: http://creativecommons.org/licenses/by-nc-nd/2.5/ 


\title{
Control system studies of an active anti-roll bar tilt system for railway vehicles
}

\author{
J T Pearson, R M Goodall and I Pratt \\ Department of Electronic and Electrical Engineering, Loughborough University, Loughborough, Leicestershire
}

\begin{abstract}
This paper describes a theoretical study of an active anti-roll bar tilt control system for a railway vehicle. It presents the rationale behind body tilting, the advantages and disadvantages associated with body tilting and the key tilt control system requirements. The paper also describes the control modelling process and presents some simulation results from control system studies. A number of competing control systems have been designed and analysed, including both classical and optimal control strategies. The performance of the control systems for a variety of curves is considered, as well as their response to track irregularities. The results show that all the strategies provide good tilting performance, the optimal control approach being marginally better.
\end{abstract}

Keywords: tilt control, active anti-roll bar, railway vehicles, active control, control systems

\section{NOTATION}

$J \quad$ cost function for the optimal control strategy

$P_{\mathrm{CT}} \quad$ comfort index related to the curve transition evaluation, representing the percentage of passengers that will feel discomfort

[Q] matrix of weighting elements for outputs $\boldsymbol{z}(t)$ in the optimal control cost function $J$

$r \quad$ weighting element for the control input used in the optimal control cost function

$R \quad$ radius of the curve $(\mathrm{m})$

$T$ anti-roll bar actuator torque $(\mathrm{N} \mathrm{m})$

$u(t) \quad$ control input to the state-space model

$V \quad$ speed of the vehicle on the curve $(\mathrm{m} / \mathrm{s})$

$\ddot{y} \quad$ maximum value of the lateral acceleration in the vehicle body, in the interval between the beginning of the curve transition and $1.6 \mathrm{~s}$ after the end of the curve transition $(\% g)$

$\dddot{y} \quad$ maximum jerk, evaluated as the maximum difference between two subsequent values of the lateral acceleration no closer than $1 \mathrm{~s}$, in the time interval between $1 \mathrm{~s}$ before the beginning of the curve transition and the end of the curve transition $(\% g / \mathrm{s})$

$z(t) \quad$ output vector from the state-space model

$\theta \quad$ track cant angle (deg)

$\phi \quad$ tilt angle $=\phi_{\mathrm{p}}+\phi_{\mathrm{s}}-\phi_{\mathrm{a}}(\mathrm{deg})$

$\phi_{\mathrm{a}} \quad$ tilt action from the actuator (deg)

$\phi_{\mathrm{p}} \quad$ primary suspension roll angle (deg)

The MS was received on 6 May 1997 and was accepted for publication on 12 August 1997. $\phi_{\mathrm{r}} \quad$ secondary suspension roll angle (deg)

$\phi_{\mathrm{s}} \quad$ wind-up in the anti-roll bar (deg)

$\dot{\phi}$ maximum absolute body roll speed, from the beginning to the end of the curve transition $(\mathrm{deg} / \mathrm{s})$

\section{BACKGROUND AND RATIONALE}

The rationale behind tilting the body of a railway vehicle during curving is straightforward and easily understood. When a railway vehicle is traversing a curve the passenger experiences a centrifugal force; similar forces act on the body and bogies, causing them to roll into or out of the curve, depending on suspension geometry and the forward speed of the vehicle. By tilting the body it is possible to reduce the lateral force perceived by the passengers (Fig. 1), thereby either allowing the vehicle to be operated at speeds in excess of those that would be acceptable to passengers in a non-tilting vehicle or providing an increase in passenger comfort for the same speed.

The active tilting of railway vehicles is now well established. Examples of tilting trains in regular service can be found in Italy $(\mathbf{1}, \mathbf{2})$, Sweden $(\mathbf{3}, \mathbf{4})$ and Japan $(\mathbf{5}, \mathbf{6})$. A number of experimental tilting trains have been investigated in the past, including research by British Rail in the United Kingdom (7) and a number are the subject of ongoing research.

Most of the trains in service that utilize an active tilt control system use either some form of inclined links or a roller bolster to provide the tilting action. Such systems require many additional components, which in turn in- 


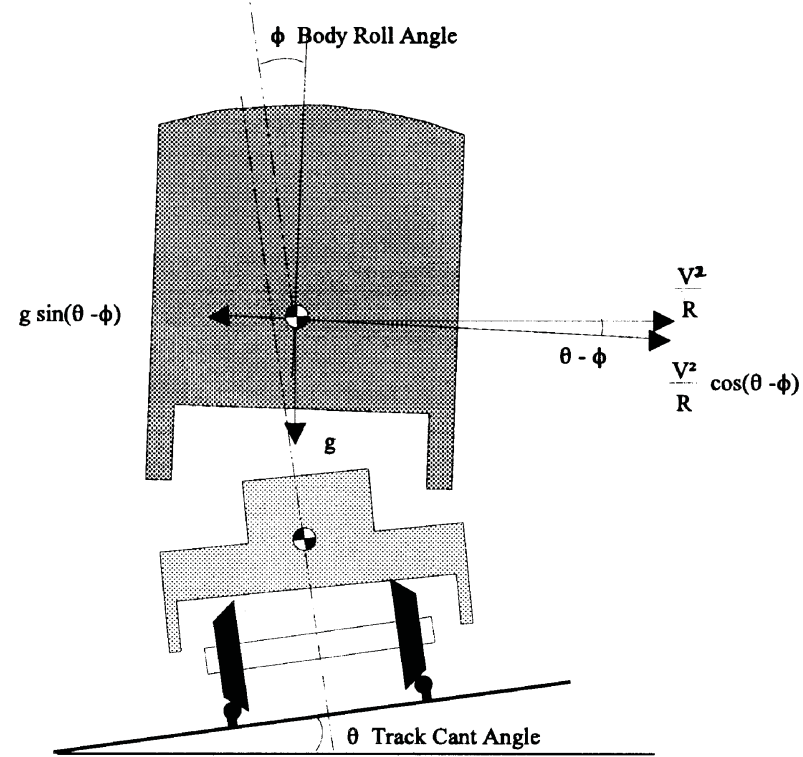

(a) No Tilt (Positive roll angle, Roll out of curve)

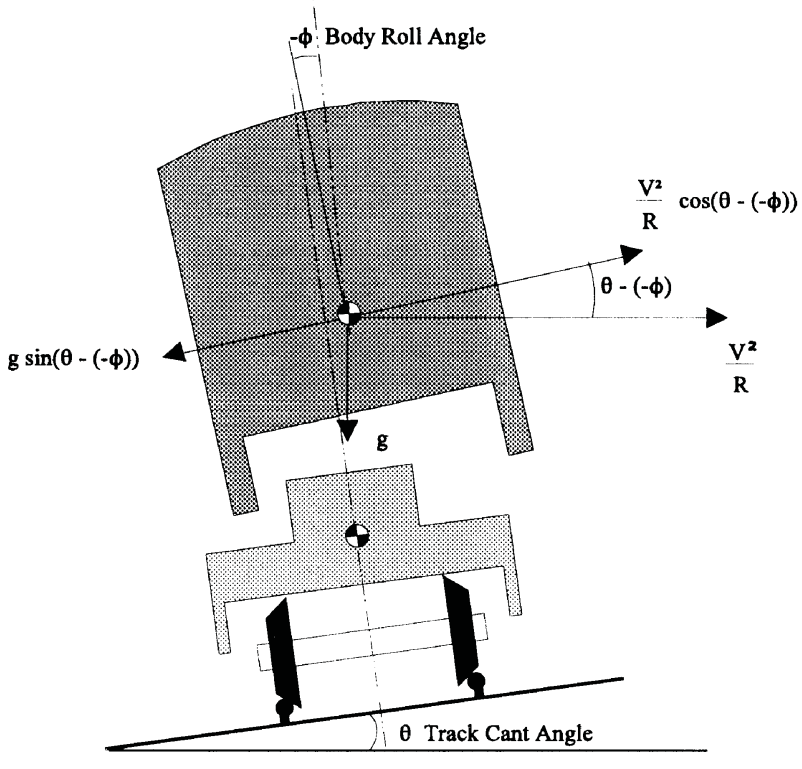

(b) With Tilt (Negative roll angle, Roll into curve)

Fig. 1 Accelerations experienced with and without tilt

crease both the weight and mechanical complexity of the bogie. The attraction of the active anti-roll bar tilting system over established methods is its simplicity and relatively low cost and weight, although it may not be as easy to provide the same degree of tilt as with other mechanisms. It offers an alternative approach to providing tilt action via the air springs $(\mathbf{8})$, for which there may be a problem due to slow response times and excessive air consumption.

\section{TILT SYSTEM REQUIREMENTS}

Implementation of active body tilting requires the following hardware and software:

(a) sensors to provide continuous measurements for the control strategy, which typically include the secondary suspension roll angle and the body lateral acceleration;

(b) a controller to determine the tilt magnitude and rate of tilt required to compensate for the lateral forces generated during curving, i.e. to generate tilt control demands and

(c) an active element or elements (hydraulic, pneumatic or electromechanical actuators) to rotate the vehicle body.

Ideal control of body tilting fundamentally requires the true cant deficiency, a quantity that is very difficult to measure from on-board the vehicle. In principle it can be inferred from measurements of track cant, vehicle speed, curvature, etc., but obtaining a true instantaneous value for cant deficiency, including the curve transitions, is an intractable problem. Most existing tilt systems use some form of lateral acceleration measurement (sometimes combined with a gyroscope to identify the start of the curve); this provides the cant deficiency information, but the signal also includes lateral acceleration associated with track irregularities, and there is a strong tendency for the tilt system action to degrade the lateral ride quality on straight track. In practice, however, it has proved possible to be successful without knowing the curve parameters explicitly. The aim of the tilt control system is to provide a smooth non-oscillatory tilting action to the body in curve transitions, while maintaining an adequate speed of response and not significantly degrading the straight-track ride quality.

\subsection{Anti-roll bar overview}

Most passenger railway vehicles have anti-roll torsion bars, sometimes known as stabilizers, in their secondary suspensions. The active anti-roll bar concept consists of adding controllable (active) elements to the anti-roll bar assembly, which can be used to tilt the vehicle body in order to reduce the lateral acceleration during curves (9). Figure 2 shows a simplified representation of the active anti-roll bar arrangement. Active anti-roll bars have been under development in the automotive field for some time (10), but the aim of the automotive systems is fundamentally different from that required of the railway tilt control system. Automotive active anti-roll bars generally aim to eliminate roll-out to give improved handling when cornering.

F00697 C) IMechE 1998 


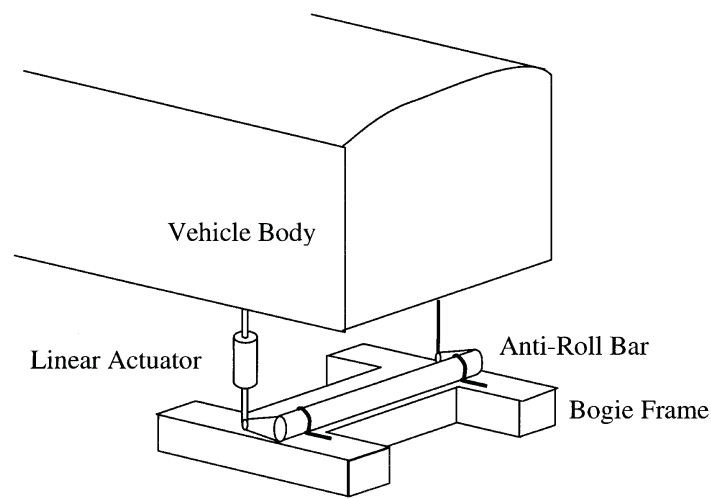

Fig. 2 Active anti-roll bar

The advantages of the active anti-roll bar over established tilting methods result from its relative simplicity, small weight increase and low cost. It can also be easily fitted as an optional extra during manufacture, or as a retrofit.

The primary disadvantage of the active anti-roll bar is that it tilts across the secondary suspension, which limits the amount by which the body can be tilted. The amount of tilt is in practice limited by factors such as vertical suspension clearances, air spring internal clearances and yaw dampers, the details of which will vary from vehicle to vehicle. The actuator will also place limitations on the tilt angle. For instance, if a linear actuator is used, then the tilt angle will be constrained by the stroke that can be obtained from the actuator within the available space.

\subsection{Tilt angle effects}

An indication of the effect of the tilt angle on the lateral acceleration felt by the passengers is given in Table 1 . The lateral acceleration is calculated using

$$
\ddot{y}=\frac{V^{2}}{R} \cos [\theta-(-\phi)]-g \sin [\theta-(-\phi)]
$$

where

$V=$ speed of the vehicle on the curve $(\mathrm{m} / \mathrm{s})$

$R=$ radius of the curve $(\mathrm{m})$

$\theta=$ track cant angle $(\mathrm{deg})$

Table 1 Effects of tilt angle

\begin{tabular}{lcccc}
\hline & $\begin{array}{c}\text { Tilt angle } \\
\phi(\mathrm{deg})\end{array}$ & $\begin{array}{c}\text { Lateral } \\
\text { acceleration } \\
\ddot{y}(\mathrm{~m} / \mathrm{s})\end{array}$ & $\begin{array}{c}\text { Reduction in } \\
\text { acceleration } \\
(\%)\end{array}$ & $\begin{array}{c}\text { Increase in } \\
\text { curving speed } \\
(\%)\end{array}$ \\
\hline Non-tilting & 0 & 1.12 & 0 & 0 \\
Tilting & 1 & 0.87 & 22 & 4.2 \\
& 2 & 0.70 & 38 & 8.3 \\
& 3 & 0.53 & 53 & 12.2 \\
& 4 & 0.37 & 67 & 16.0 \\
& 5 & 0.20 & 82 & 19.6 \\
6 & 0.03 & 97 & 23.1 \\
\hline
\end{tabular}

F00697 (C) IMechE 1998

$$
\begin{aligned}
& \phi_{\mathrm{p}}=\text { primary suspension roll angle }(\mathrm{deg}) \\
& \phi_{\mathrm{s}}=\text { wind-up in the anti-roll bar }(\mathrm{deg}) \\
& \phi_{\mathrm{a}}=\text { tilt action from the actuator }(\mathrm{deg}) \\
& \phi=\text { tilt angle }=\phi_{\mathrm{p}}+\phi_{\mathrm{s}}-\phi_{\mathrm{a}}
\end{aligned}
$$

The curve used as the test case for these calculations had an assumed radius of $1.35 \mathrm{~km}$, with a track cant angle of $5.7^{\circ}$. It was assumed that the nominal speed of the vehicle on the curve was $180 \mathrm{~km} / \mathrm{h}$, and that the primary suspension rolled out to an angle of $0.6^{\circ}$.

Table 1 shows the percentage reduction in lateral acceleration felt by the passengers for a given tilt angle. It also shows the corresponding percentage increase in curving speed that can be achieved for a given tilt angle, based on the lateral acceleration felt by the passengers being equal to that on a slower non-tilting train.

\subsection{Tilt system assessment}

The operation of the control system during curve transitions is particularly important, the main objective being that it should not degrade the ride comfort compared with a passive suspension at non-tilting vehicle speeds.

The amount of tilt and rate of tilt provided by the control system need to correspond to the increasing lateral acceleration as the vehicle negotiates the curve transition. A controller that is too responsive may provide high roll rates and jerk levels, both of which are unacceptable. Conversely, a sluggish controller will provide low roll rates and jerk levels, but may not be responsive enough, allowing the lateral acceleration to increase unchecked as the vehicle negotiates the curve before eventually compensating by tilting the body. This problem would be magnified on reverse curves, where the opposite extremes of available tilt are required directly one after another.

The lateral body acceleration response of a vehicle to a curve consists of the following components:

(a) a component due to body tilt and the deterministic features of the track (cant and curvature);

(b) a component due to the dynamic response of the suspension to both deterministic and stochastic track features.

The ideal acceleration response would be a smooth nonoscillating increase in acceleration up to the steady value on the curve. The aim of the control system is therefore to provide an acceptable ride quality in terms of lateral acceleration, roll rate and jerk through curve transitions, where the required magnitude of body tilt and the rate of change in tilt vary continuously.

Another important objective of the control system performance is that it needs to react to changes in track curvature and cant, but not to track irregularities (stochastic or random track features). Reacting to these not only increases the actuator power requirements but also degrades the straight-line and curving ride provided by the suspension. A control system tuned to provide good 
performance during curve transitions may not necessarily provide a comparable level of ride on straight track to a vehicle with a passive suspension. In fact, this is often the fundamental compromise for any tilt control system and can be summarized as a trade-off between the curve transition response and the straight-line performance.

In summary, there are three aspects to ride quality, namely straight-track performance (random track features about a zero mean), constant curving performance (random track features imposed about a steady-state value) and performance on curve transitions between straight track and constant-radius curves. Throughout this paper the first two aspects are referred to as the stochastic performance criteria and the third aspect is referred to as the deterministic performance criterion.

\subsection{Control system performance specifications}

The control system objectives discussed in the previous section can be transformed into a set of performance specifications for the control system. A maximum tilt angle of $2.5^{\circ}$ is used, since the intended application is initially for a duo-spring, in-board bearing bogie. This should give a speed-up factor of 10 per cent on curves for tilting vehicles as compared with non-tilting vehicles (Table 1). The design speed for the passive suspensions is taken to be $180 \mathrm{~km} / \mathrm{h}$ $(50 \mathrm{~m} / \mathrm{s})$, and therefore the design speed for the active tilting suspension is $200 \mathrm{~km} / \mathrm{h}(55 \mathrm{~m} / \mathrm{s})$.

The transition response specification is more involved because the ride perceived by the passengers is no longer dominated by the lateral acceleration, but now also comprises significant components of jerk and roll rate owing to the continuously changing track curvature and cant. The evaluation of passenger comfort on curve transitions uses a method developed by British Rail, which is based on direct observations from real transitions (11). Two equations are specified, one for seated passengers and one for standing passengers. Clearly the most uncomfortable position is standing, and therefore the suspension is designed for this case. The equation used for standing passengers is

$$
P_{\mathrm{CT}}=|(2.80 \ddot{y}+2.03 \dddot{y}-11.1)|_{\geqslant 0}+0.185 \dot{\phi}^{2.283}
$$

where

$P_{\mathrm{CT}}=$ comfort index related to the curve transition evaluation, representing the percentage of passengers that will feel discomfort

$\ddot{y}=$ maximum lateral acceleration in the vehicle body, in the interval between the beginning of the curve transition and $1.6 \mathrm{~s}$ after the end of the curve transition $(\% g)$

$\dddot{y}=$ maximum jerk, evaluated as the maximum difference between two subsequent values of the lateral acceleration no closer than $1 \mathrm{~s}$, in the time interval between $1 \mathrm{~s}$ before the beginning of the curve transition and the end of the curve transition $(\% \mathrm{~g} / \mathrm{s})$

$\dot{\phi}=$ maximum absolute body roll speed, from the beginning to the end of the curve transition (deg/s), where the dot signifies the derivative with respect to time $t$

These parameters are shown for a typical curve transition in Fig. 3.

Based on these considerations, the performance criteria for the tilt control system are:

1. Deterministic performance criterion. The combination of body roll rate, jerk and lateral acceleration must be optimized so that the active tilt control system provides the same value of $P_{\mathrm{CT}}$ at $55 \mathrm{~m} / \mathrm{s}$ as the passive nontilting suspension provides at $50 \mathrm{~m} / \mathrm{s}$.

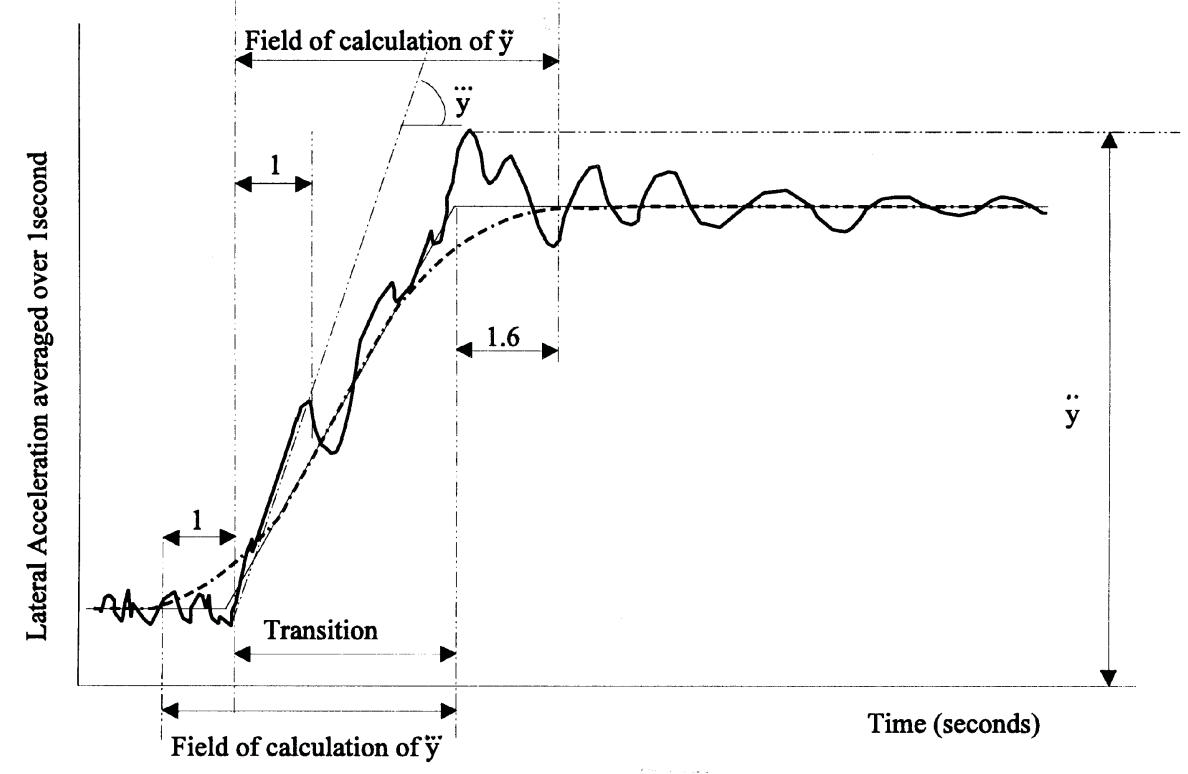

Fig. 3 Calculation of comfort during curve transitions 
2. Stochastic performance criteria. The straight-line or constant-curvature ride quality (weighted r.m.s. acceleration measured in $\mathrm{mg}$ ) performance of the active tilting suspension should not be degraded by the tilt control system by any more than 7.5 per cent of that provided by a passive suspension system at the same speed of $55 \mathrm{~m} / \mathrm{s}$ (this represents the threshold at which the degradation becomes perceptible). It should be noted, however, that the ride quality provided by the tilting suspension on curves will inevitably be degraded by more than 7.5 per cent of that provided by a passive suspension as a consequence of the higher speed of operation, but this is a feature shared by all tilting trains.

\section{BASIC CONTROL STRATEGIES FOR TILT}

There are a number of approaches that can be used for controlling tilt systems, and it is useful to classify these in a general sense before moving on to the specific issues relating to the active anti-roll bar solution. These strategies can be broadly divided into two major types: nulling controllers and command-driven controllers.

It is largely accepted that full compensation for cant deficiency is not appropriate from the point of view of passenger perception, a consequence of the comfort index identified in Section 2.4, and tilt controllers must therefore accommodate partial tilt strategies. In addition to this, there may be a physical limit to the tilt action of the particular tilt mechanism, in which case there may be another decision with respect to the tilt controller: does it conform with the chosen control law until the tilt limit is reached or should it provide reduced pro rata action throughout the full operating regime?

\subsection{Nulling control}

Nulling control strategies use a feedback arrangement, where the control system attempts to drive the tilt feedback signal to zero. An example of this is where the lateral acceleration is measured using an accelerometer mounted on the vehicle body (12). As the body is tilted, the measured acceleration will be reduced to zero, and consequently the lateral acceleration felt by the passengers will also be zero. Partial tilt action can be achieved by including an appropriate proportion of the applied tilt angle as a positive feedback within the system (Fig. 4a).

The main advantage with the nulling control strategy is that the sensors are mounted on the vehicle body and hence do not need to be capable of withstanding the harsh vibration environment experienced by bogie-mounted sensors. The secondary suspension is in effect a mechanical filter, and therefore body-mounted sensors do not detect the high levels of acceleration experienced on the bogie; consequently, the signals from these sensors require less processing. Clearly, with this type of strategy the sensor is within the control loop. This causes interaction between suspension and controller dynamics, which may result in stability problems. This is in fact the primary disadvantage of this strategy.

\subsection{Command-driven control}

The stability problems caused by the accelerometer being within the control loop can be avoided by obtaining the control signal from something unaffected by the suspension response to tilt (i.e. outside the control loop), e.g. by tilting above the secondary suspension and about a point near to the centre of gravity or by using a bogie-mounted accelerometer.

Strategies that derive a tilt control signal from a bogiemounted accelerometer fall into the class of tilt strategies that can be called command-driven strategies, in which case the applied tilt angle will also be used as a feedback signal to control the tilt action (Fig. 4b). Partial tilt can be achieved by applying a factor less than unity to the command signal ( $K<1$ in Fig. 4b). An important feature of these strategies is that the demand signal is largely unaffected by the tilt action, although it should be noted that there will still be some minor interaction via the tilt action's impact on the primary suspension.

Most current tilt control systems use an accelerometer mounted on the bogie to measure the lateral acceleration. However, the bogie is a harsh vibration environment, and for the control system to distinguish the track design features the output from the bogie accelerometer must be low-pass filtered to remove the unwanted high-frequency content, essentially that associated with lateral track roughness. Owing to the level of filtering required, the delay introduced by the filter is significant, but can be overcome by using preview (Fig. 4c), i.e. by mounting the accelerometer on the bogie of the vehicle in front. In doing this both the speed and direction of travel become important factors for the correct operation of the tilt system.

There are a number of other options for deriving the tilt control signal, including:

(a) a body yaw gyro combined with a measurement of speed to obtain an estimate of cant deficiency and

(b) a track database which could be indexed on the basis of position [position can be readily obtained from satellite-based global positioning systems (GPS), although there are safety implications in their use].

\section{CONTROL SYSTEM STUDIES}

The objective of the tilt control system has already been discussed. From a control system viewpoint this can be interpreted as increasing the response of the system at low frequencies (deterministic track features), reducing the response of the system to high-frequency inputs (track irregularities) and ensuring stable operation. The control input consists of an angular displacement provided by a rotary actuator acting in series with the anti-roll bar, effectively providing a torque input to the body. 


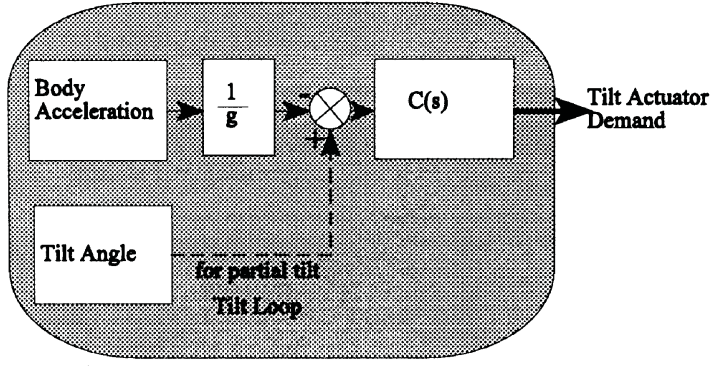

(a) Nulling Control Strategy

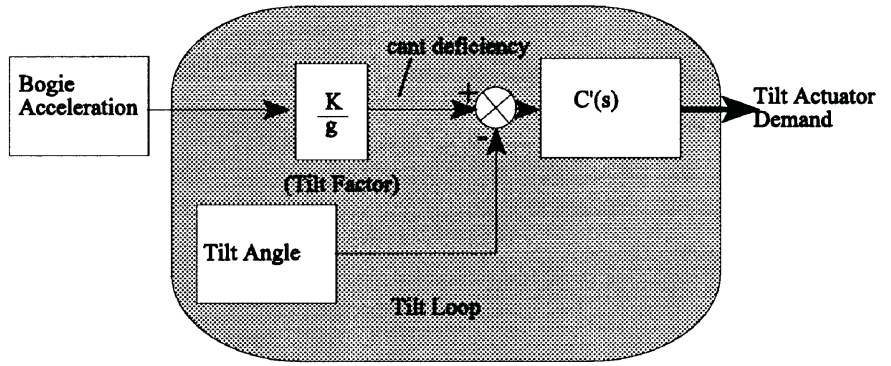

(b) Command-Driven Control Strategy

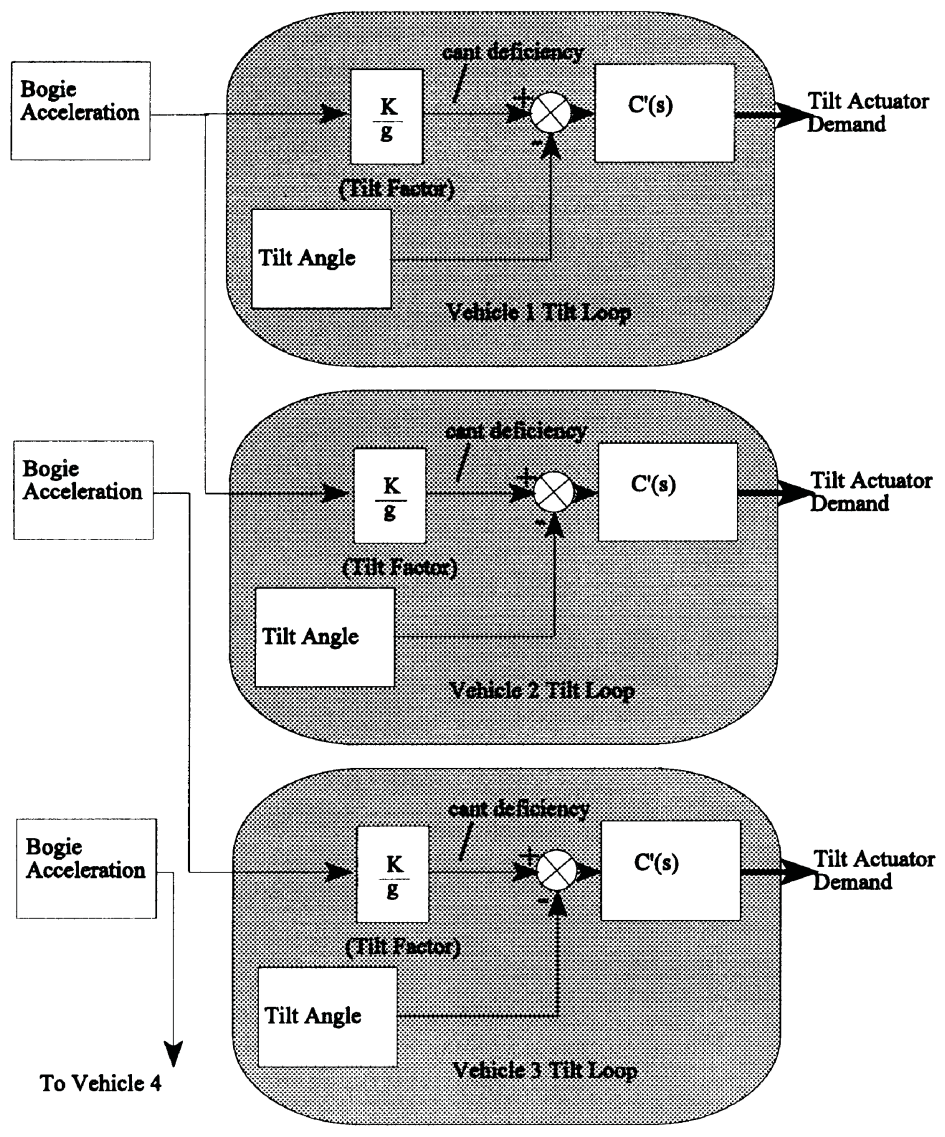

(c) Command-Driven Control Strategy with Precedence

Fig. 4 Strategies for partial tilt

The parameters used for the models in the simulation study are listed below (bogie kinematic modes have been ignored):

Secondary suspension stiffness (vertical)

Primary suspension stiffness (vertical)

Secondary suspension damping (vertical)

Primary suspension damping (vertical)

Air-spring reservoir stiffness
$620.0 \mathrm{kN} / \mathrm{m}$

$6.0 \mathrm{MN} / \mathrm{m}$

$50.0 \mathrm{kN} \mathrm{s} / \mathrm{m}$

$200.0 \mathrm{kN} \mathrm{s} / \mathrm{m}$

$244.0 \mathrm{kN} / \mathrm{m}$
Air-spring area stiffness

Body mass

Bogie mass

Body roll inertia

Bogie roll inertia

Primary lateral damping

Primary lateral stiffness

Secondary lateral damping

Secondary lateral stiffness

Secondary lateral suspension spacing (body centre of gravity)

Secondary lateral suspension spacing (bogie centre of gravity)
$210.0 \mathrm{kN} / \mathrm{m}$ $38000.0 \mathrm{~kg}$ $5000.0 \mathrm{~kg}$ $50.0 \mathrm{kN} \mathrm{m} \mathrm{s}^{2} / \mathrm{rad}$ $3.0 \mathrm{kN} \mathrm{m} \mathrm{s}^{2} / \mathrm{rad}$ $32.0 \mathrm{kN} \mathrm{s} / \mathrm{m}$ $140.0 \mathrm{MN} / \mathrm{m}$ $33.0 \mathrm{kN} \mathrm{s} / \mathrm{m}$ $520.0 \mathrm{kN} / \mathrm{m}$ $0.90 \mathrm{~m}$

$0.25 \mathrm{~m}$ 
Primary lateral suspension spacing $\quad-0.09 \mathrm{~m}$ (bogie centre of gravity)

Primary vertical suspension spacing $\quad 1.0 \mathrm{~m}$

Secondary vertical suspension spacing $0.9 \mathrm{~m}$

Roll bar stiffness

3.0 MN/m

\subsection{Classical control schemes}

The classical control schemes require measurement of the cant deficiency and the secondary suspension roll angle. When the tilt limits are included in the control system there are two tilting regimes:

(a) tilting the body by feeding back lateral acceleration for tilt angles less than $2.5^{\circ}$ (i.e. partial compensation); and

(b) maintaining the tilt angle at $2.5^{\circ}$ by feeding back the secondary suspension roll angle, for tilt angles greater than $2.5^{\circ}$ (i.e. full compensation up to the tilt limit).

The control system design task can be partitioned into subsystems for lateral acceleration feedback and a combination of subsystems for tilt angle feedback. The frequency response of the lateral acceleration and secondary suspension roll angle to the tilt actuator input are shown on Nichols plots in Figs 5 and 6, and these responses enable suitable compensators to be designed for the control loops.

The Nichols chart of the roll-angle feedback shows that introducing a simple gain term into the system will improve the low-frequency response and improve the stability margin. However, the Nichols chart of the lateral acceleration feedback is close to instability owing to interactions with the suspension dynamics, and although introducing a straight gain term will improve the low-frequency response, it will also make the control system unstable. Reducing the gain at higher frequencies can rectify this, and this will also improve the vehicle ride by reducing the response of the system to track irregularities. In practice, this can be achieved by using a low-pass filter. Clearly the choice of the filter cut-off frequency directly affects the performance of the system in terms of its ability to respond rapidly to curve inputs while at the same time not responding to track irregularities. Defining the frequency that separates track features into deterministic and stochastic features is not easy, and in this study it was determined through simulations using real track data.

The full compensation strategy consists of a low-pass filter, tilt limits and a gain of 1.0; for the partial compensation strategy it consists of a low-pass filter, tilt limits and a gain of 0.3 . The gain of 0.3 provided a $2.5^{\circ}$ tilt at $55 \mathrm{~m} / \mathrm{s}$ on a curve of $1275 \mathrm{~m}$ radius with $150 \mathrm{~mm}$ of cant. The full and partial control system structures are shown in detail in Fig. 7.

There are a number of subtle differences between the partial and full compensation strategies. Figure 8 shows theoretical simplified acceleration levels for a passive suspension and for both the classical strategies when running on to a curve transition of length $L=136 \mathrm{~m}$ with an installed cant of $6^{\circ}$. Consideration of the gradient of these lines provides an indication of the jerk levels produced by the different strategies. If the curve representing the passive suspension at the nominal speed $(50 \mathrm{~m} / \mathrm{s}$ or $180 \mathrm{~km} / \mathrm{h}$ ) is normalized to provide a jerk level of 1 (this corresponds to a jerk level of $0.45 \mathrm{~m} / \mathrm{s}^{3}$ ), then the curve for

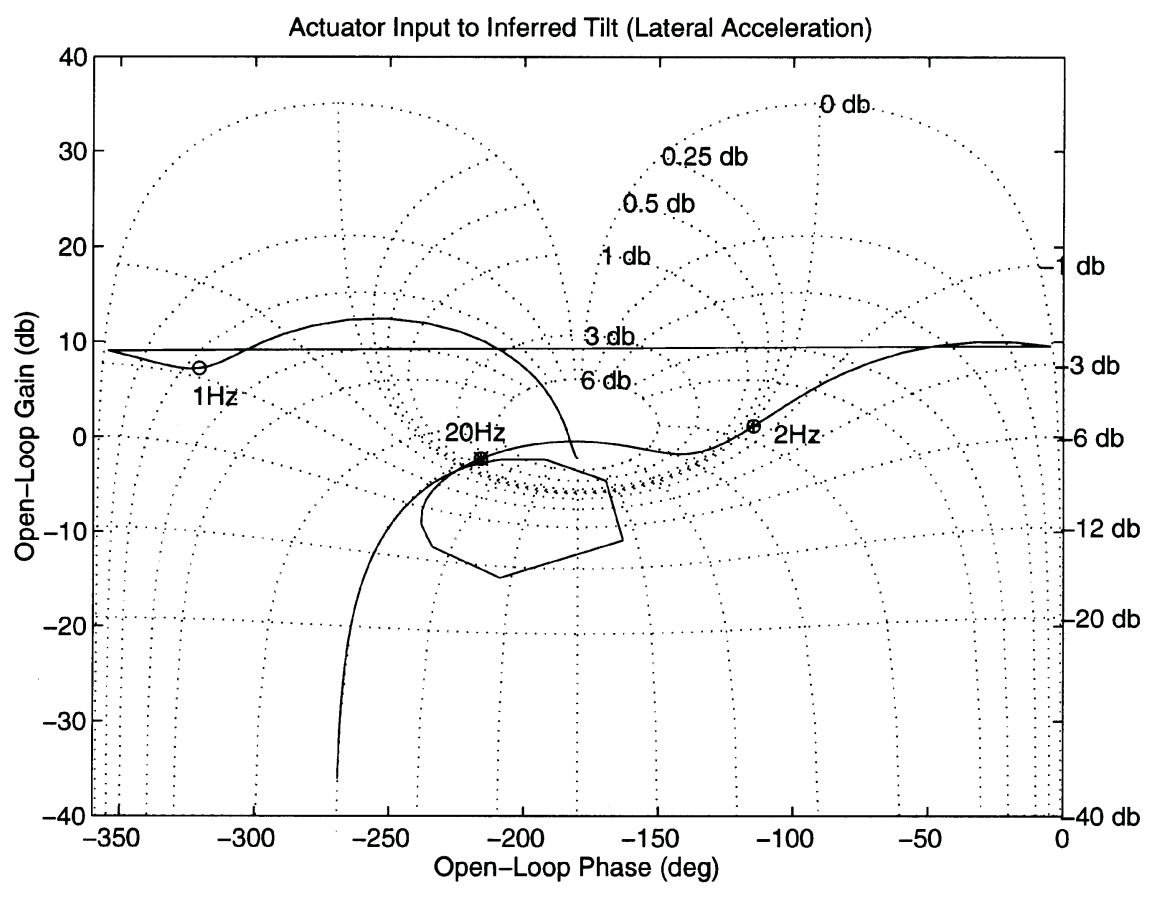

Fig. 5 Nichols plot for lateral acceleration 


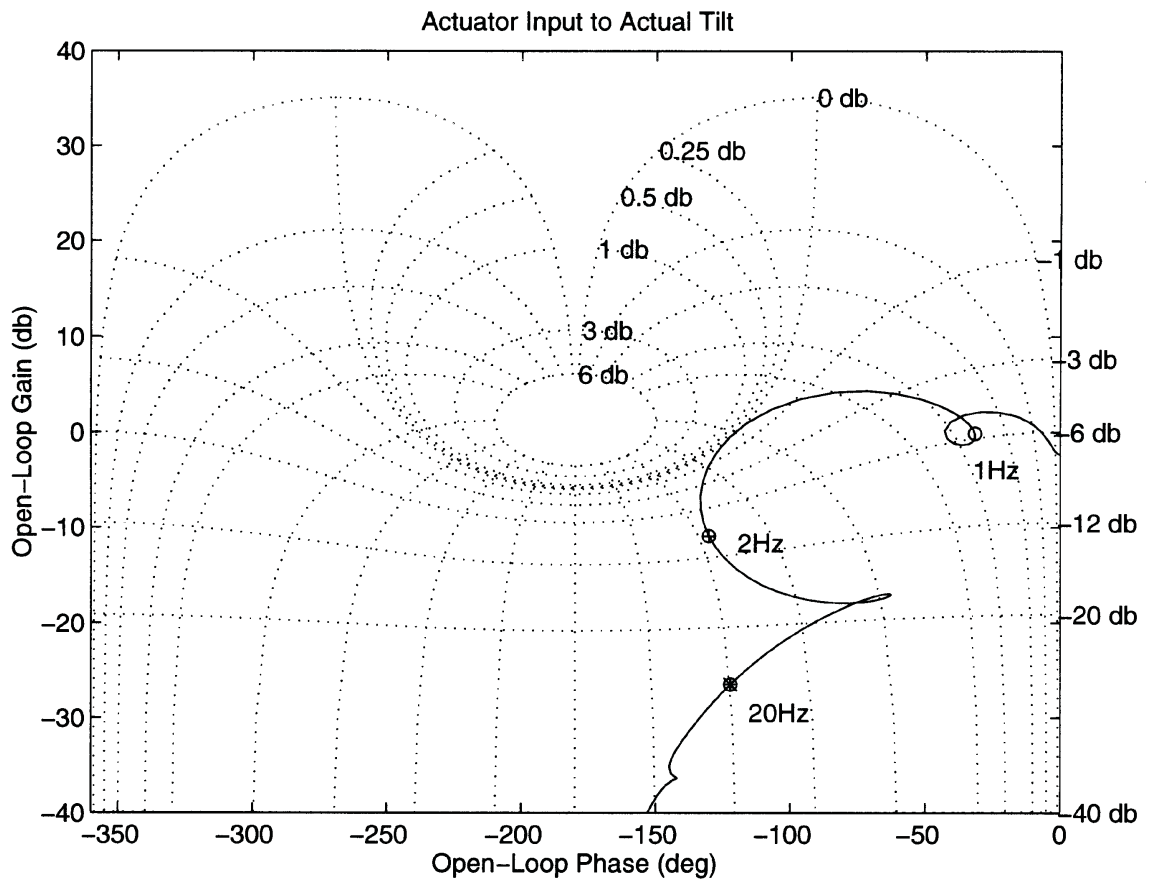

Fig. 6 Nichols plot for secondary suspension roll angle

FULL COMPENSATION

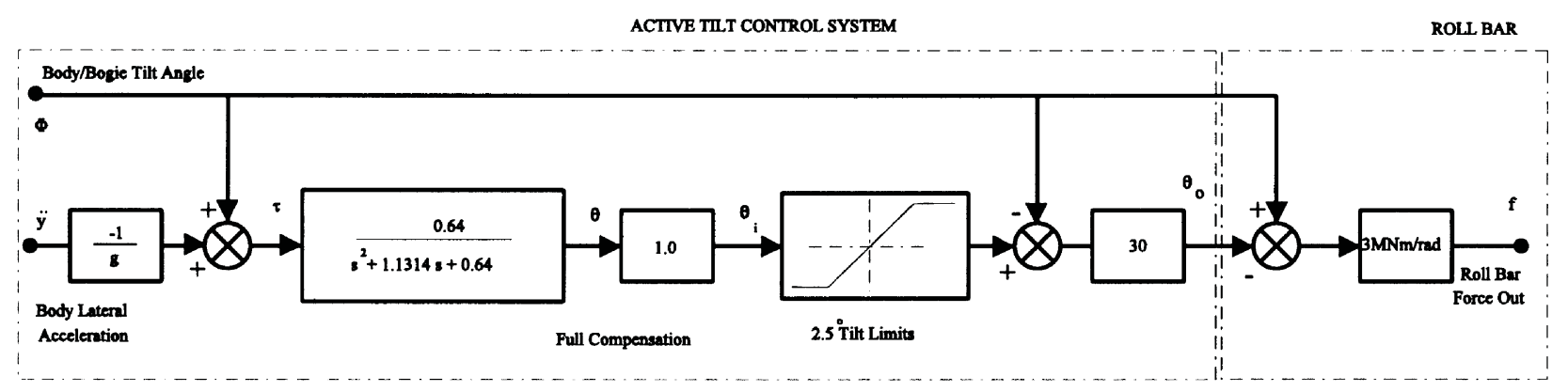

PARTIAL COMPENSATION

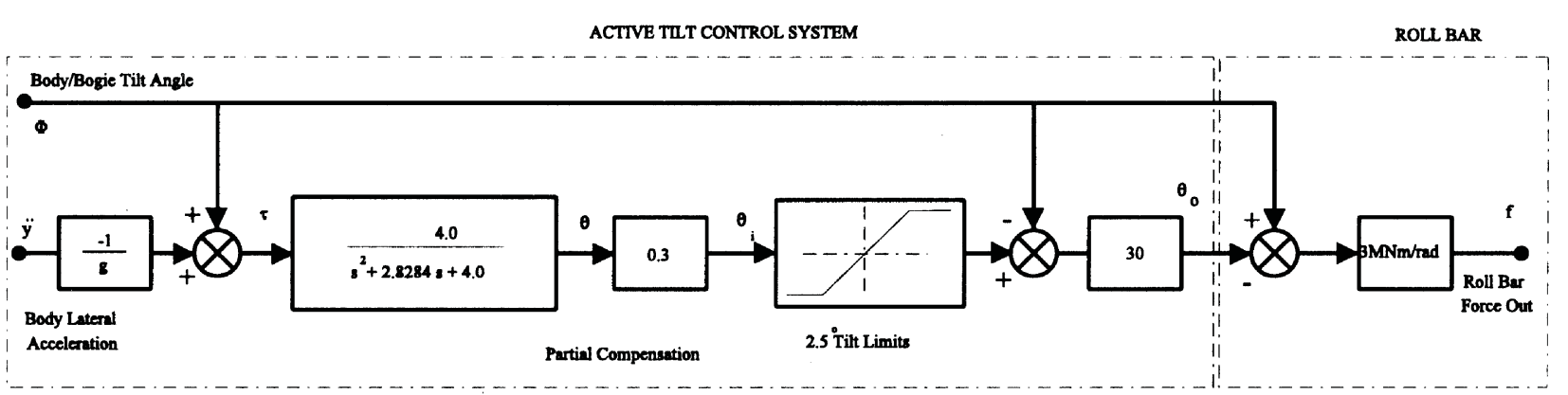

Fig. 7 Full and partial tilt control strategies with limited tilt angle

the passive suspension at the nominal speed plus 10 per cent $(55 \mathrm{~m} / \mathrm{s}$ or $200 \mathrm{~km} / \mathrm{h})$ provides a relative jerk level of

$$
(1.0+10 \%)\left(\frac{8.5}{6.0}\right)=1.56
$$

This is also the slope of the curve for the full compensation limited tilt strategy, since in theory it compensates fully up to $2.5^{\circ}$ of tilt, and then the acceleration increases at the same rate as the uncompensated case as shown in Fig. 8, although in reality the slope of this line may be less steep 


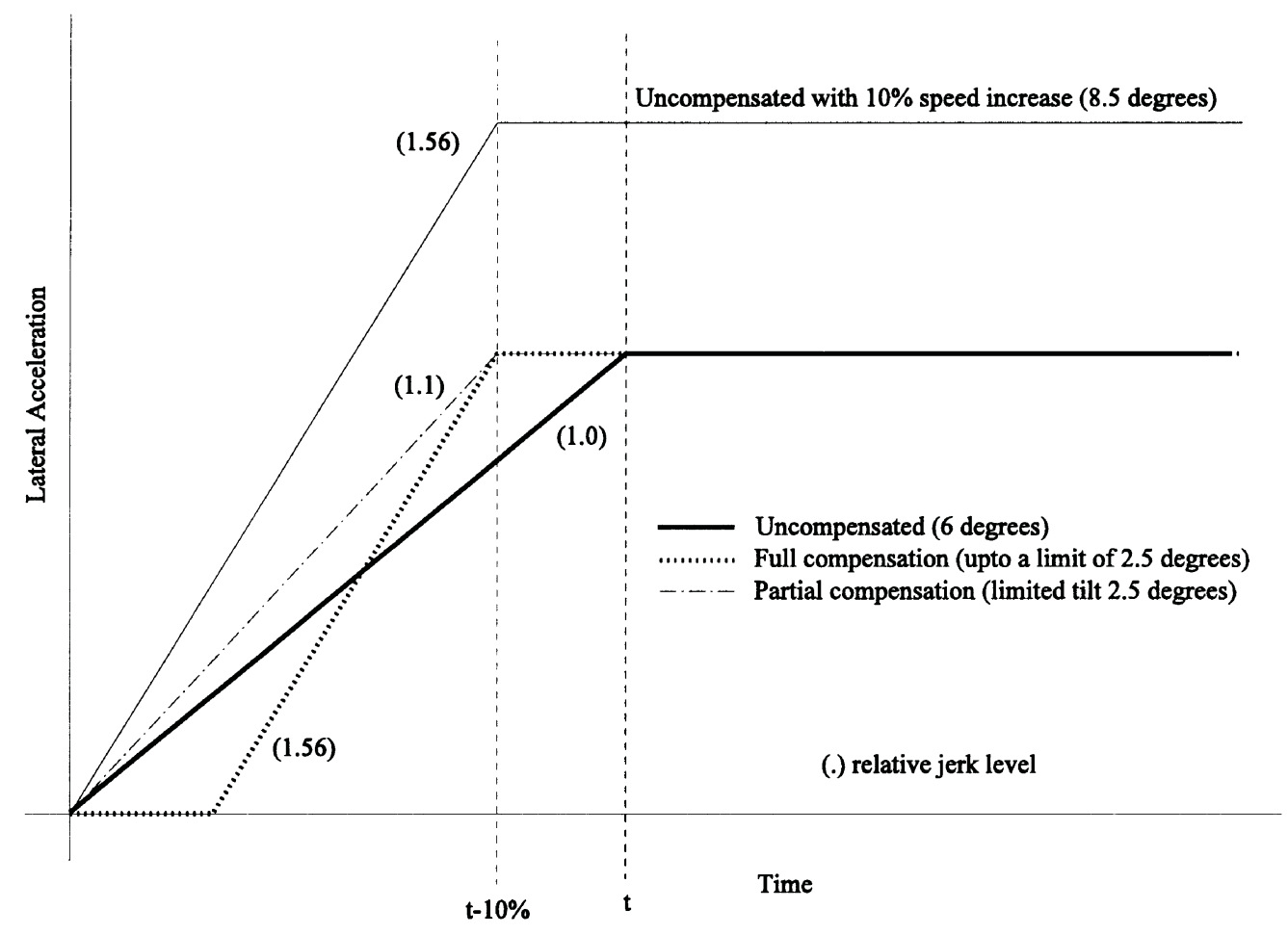

Fig. 8 Theoretical performance of full and partial tilt control strategies

owing to the dynamics of the control system. The slope of the partial compensation curve is simply 10 per cent greater than that of the passive suspension at the nominal speed $(50 \mathrm{~m} / \mathrm{s})$, i.e. a relative jerk level of 1.1 . In summary, the relative jerk levels are:

$\begin{array}{ll}\text { Passive suspension at } 50 \mathrm{~m} / \mathrm{s} & 1.00 \\ \text { Passive suspension at } 55 \mathrm{~m} / \mathrm{s} & 1.56 \\ \text { Full compensation limited tilt at } 55 \mathrm{~m} / \mathrm{s} & 1.56 \\ \text { Partial compensation at } 55 \mathrm{~m} / \mathrm{s} & 1.10\end{array}$

As well as increased jerk levels, the full compensation strategy will also have higher roll rates than the partial compensation strategy, and even up to $2.5^{\circ}$ full compensation may prove to be uncomfortable for passengers. These effects mean that the full compensation strategy will also have higher peak actuator power requirements. A major drawback of the partial strategy is that at speeds less than the design speed the strategy does not use the full $2.5^{\circ}$ of available tilt, whereas the full compensation strategy will use the maximum allowable tilt.

The classical control schemes have the advantage that the only parameter to be tuned is the filter break frequency. Tuning is accomplished by varying this frequency and calculating the performance of the controller on a typical curve transition and on a straight piece of typical goodquality main line track. The aim is to optimize the transition performance while not degrading the straight-line performance by more than 7.5 per cent of the performance of the passive suspension.

\subsection{Modern control scheme}

The modern control scheme is based on optimal control theory and requires all state variables to be available for feedback through a gain matrix. If some of the states are unavailable, then a state estimation technique can be employed at the expense of controller complexity. An optimal controller in its simplest form consists of a set of gains, but an observer requires a model of the system, resulting in a controller that is of a similar order to the system being controlled. A simple end-view representation was used to generate a mathematical model for the optimal control system design, shown in Fig. 9a. The state-space model is naturally formulated with the following states: bogie lateral displacement, bogie lateral velocity, bogie roll angle, bogie roll rate, body lateral displacement, body lateral velocity, body roll angle and body roll rate. However, feeding back such variables as body displacement and body velocity, which on a steady curve (constant acceleration) increase rapidly, proves problematic when a control system designed on a simple model is implemented on a more complex and realistic model. By reformulating the state-space model so that only differential displacements and velocities are fed back, this situation can be avoided. The reformulated states, $x(t)$, are as follows: bogie-track differential lateral displacement, bogie-track differential lateral velocity, bogie roll angle, bogie roll rate, body-bogie differential lateral displacement, body-bogie differential lateral velocity, body roll angle and body roll rate. The control input, $u(t)$, is the roll actuator angle. The 


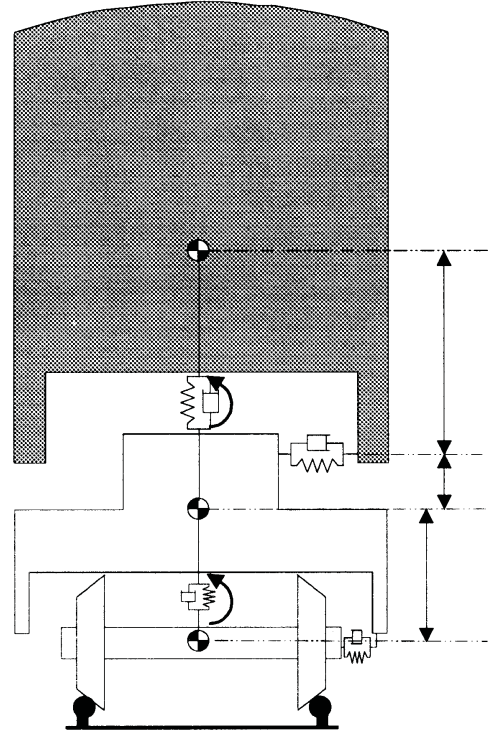

(a)

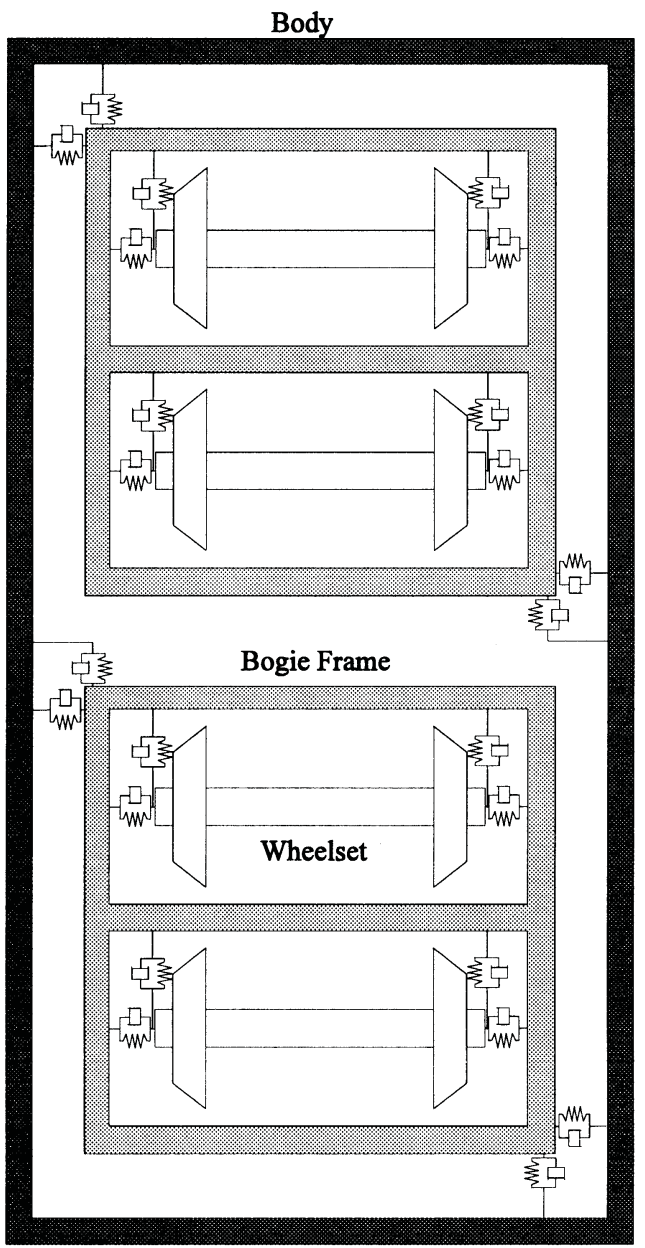

(b)

Fig. 9 (a) End-view model and (b) plan-view model outputs, $z(t)$, are defined as the secondary suspension roll angle, the lateral suspension force (included for active lateral suspension implementation), the lateral acceleration and the secondary suspension roll rate.

It is a relatively straightforward task to augment the state-space model with extra outputs, or even extra inputs. A useful extension would be to include a lateral force actuator in the secondary suspension to improve the lateral ride. For the state-space model this would simply involve defining an extra column in the input matrix.

Since the aim is to minimize the outputs defined previously, the cost function is defined as

$$
J=\int_{0}^{\infty}\left(z^{\mathrm{T}}(t)[\mathbf{Q}] z(t)+u^{\mathrm{T}}(t) r u(t)\right) \mathrm{d} t
$$

where $r$ is a weighting factor applied to the control input and $[\mathbf{Q}]$ is a diagonal matrix of weighting factors for the outputs. The elements in [Q] and $r$ were initially chosen to be $1 /(\text { expected value })^{2}$ for each of the parameters. By varying these weighting factors and calculating the transition and straight-track performance of the complete system, the controller was tuned using the same methodology as for the classical control strategies.

The lateral cant deficiency was used to offset the secondary suspension roll angle, which was then limited to a maximum of $2.5^{\circ}$. By formulating the optimal controller to control this offset secondary suspension roll angle, the body was tilted on curves up to a maximum of $2.5^{\circ}$, thereby reducing the lateral acceleration felt by the passengers. Ideally the lateral acceleration should be controlled directly, but it proved difficult to formulate the model so that the control strategy would reduce the lateral acceleration by tilting the body correctly. Also, it would be very difficult to guarantee tilt limits of $2.5^{\circ}$ if the lateral acceleration were minimized directly.

\subsection{Complete vehicle control systems}

The previous descriptions have been applied to designing a control system using the end-view model, which of course neglects the fact that the vehicle has two ends and two bogies (in practice the active anti-roll bar system will be implemented using an active anti-roll bar at each end of the vehicle). There are a number of possible control system arrangements which can be used to control two active antiroll bars (see Fig. 10):

1. Independent control systems for each of the active antiroll bars.

2. A symmetric control system. This system averages the signals from each end of the vehicle (tilt and acceleration) and drives each actuator with the same signal. The trailing actuator benefits from half-vehicle preview, although the signal to the leading actuator is delayed. 


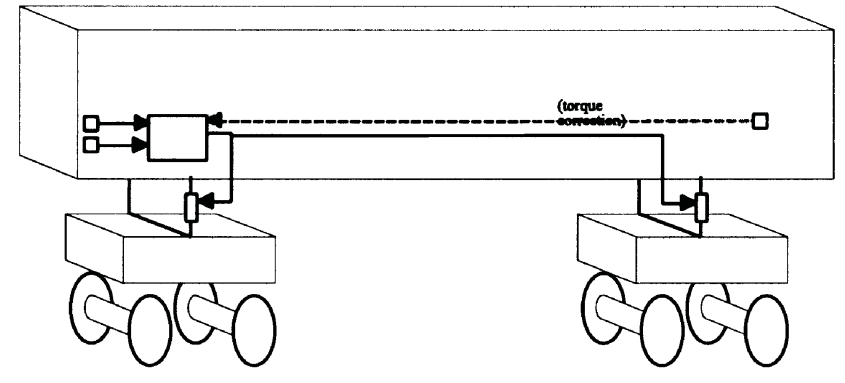

MASTRRSLAVE TULT CONTROL SYSTEM

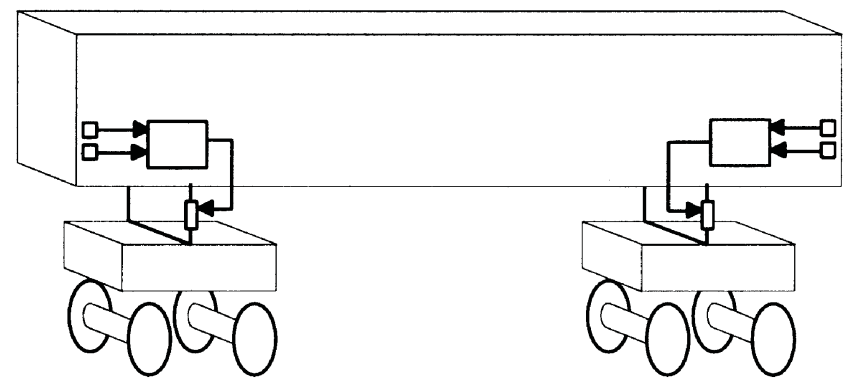

INDEPENDENT TLLT CONTROL SYSTEMS

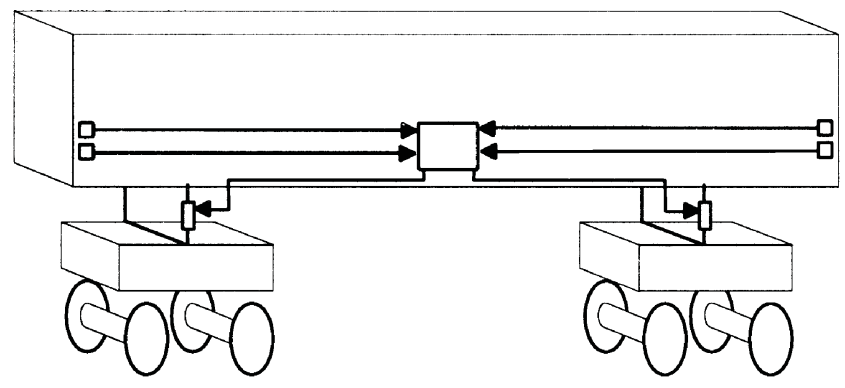

SYMMETRIC TULT CONTROL SYSTEMS

Fig. 10 Complete vehicle control system

3. A master/slave control system. This system uses the signals from one end of the vehicle to calculate drive signals for both actuators. This arrangement is directionally sensitive, but has the advantage that the slave actuator essentially has full vehicle preview.
It is also necessary to decide which feedback variable should be used to control the actuators: the torque produced by the actuator (which allows for anti-roll bar stiffness) or the actuator length alone. This issue is clearly of practical significance for implementation, but is also important when it comes to assessing full vehicle strategies.

\section{SYSTEM PERFORMANCE}

The control systems were tuned using the end-view model. Once tuned, the control system parameters are transferred to the more comprehensive full vehicle model (excluding vertical modes) for further analysis (Fig. 9b). The following subsections present results from both the end-view and full vehicle models.

\subsection{Single-end model results}

A consequence of the quick response of the classical full compensation strategy is that it produces high roll rates and high jerk levels. High jerk levels are also produced by this strategy as it switches between acceleration feedback and roll angle feedback. This problem was solved by moving the position of the tilt limits to before the filter, which effectively filtered the effects of the discontinuities in the limits. The performance (see Section 2.4) of the tuned control strategies is given in Table 2, along with the performance of the passive suspension for comparison. Measurements are taken at the centre of gravity of the body unless otherwise stated.

The apparent discrepancies between the passive results at 50 and $55 \mathrm{~m} / \mathrm{s}$ (jerk and roll) are due to the interaction of the suspension dynamics with the curve geometry. Similarly, the discrepancy with the random performance is due to the use of actual track data.

Table 3 shows the performance of the strategies on a variety of test curves (test curves are described in the Appendix). As expected, the reverse curve (test 2) was a particularly severe test. Figure 11 shows the lateral acceleration for the various strategies on test curve 2 and Fig. 12 shows the body jerk levels. The secondary suspension roll angles are shown in Fig. 13. Figure 14

Table 2 Basic performance of passive and active anti-roll bars (end-view model)

\begin{tabular}{|c|c|c|c|c|c|}
\hline \multirow{2}{*}{$\begin{array}{l}\text { Tilt strategy } \\
\text { performance }\end{array}$} & \multicolumn{2}{|c|}{ Passive } & \multirow{2}{*}{$\begin{array}{l}\text { Active, full } \\
\text { compensation } \\
\text { at } 55 \mathrm{~m} / \mathrm{s}\end{array}$} & \multirow{2}{*}{$\begin{array}{c}\text { Active, optimal } \\
\text { control } \\
\text { at } 55 \mathrm{~m} / \mathrm{s}\end{array}$} & \multirow{2}{*}{$\begin{array}{c}\text { Active, partial } \\
\text { compensation } \\
\text { at } 55 \mathrm{~m} / \mathrm{s}\end{array}$} \\
\hline & $50 \mathrm{~m} / \mathrm{s}$ & $55 \mathrm{~m} / \mathrm{s}$ & & & \\
\hline Acceleration $\left(\mathrm{m} / \mathrm{s}^{2}\right)$ & 1.248 & 1.667 & 1.250 & 1.195 & 1.279 \\
\hline Jerk $\left(\mathrm{m} / \mathrm{s}^{3}\right)$ & 1.605 & 1.574 & 1.563 & 1.546 & 1.568 \\
\hline Roll rate $(\mathrm{deg} / \mathrm{s})$ & 2.820 & 2.602 & 3.125 & 3.233 & 3.279 \\
\hline Acceleration factor $(\%)$ & 35.61 & 47.59 & 35.68 & 34.11 & 36.50 \\
\hline Jerk factor $(\%)$ & 33.21 & 32.56 & 32.35 & 31.99 & 32.44 \\
\hline Roll rate factor $(\%)$ & 1.97 & 1.64 & 2.49 & 2.70 & 2.78 \\
\hline$P$ value $(\%)$ & 59.69 & 70.70 & 59.42 & 57.90 & 60.62 \\
\hline $\begin{array}{l}\text { Random (straight-track) } \\
\text { performance }(\mathrm{mg})\end{array}$ & 26.58 & 25.05 & 28.55 & 28.55 & 28.59 \\
\hline
\end{tabular}


Table 3 Performance of passive and active anti-roll bars (end-view model)

\begin{tabular}{|c|c|c|c|c|c|}
\hline \multirow{2}{*}{$\begin{array}{l}\text { Tilt strategy } \\
\text { performance }\end{array}$} & \multicolumn{2}{|c|}{ Passive } & \multirow{2}{*}{$\begin{array}{l}\text { Active, full } \\
\text { compensation } \\
\text { at } 55 \mathrm{~m} / \mathrm{s}\end{array}$} & \multirow{2}{*}{$\begin{array}{c}\text { Active, optimal } \\
\text { control } \\
\text { at } 55 \mathrm{~m} / \mathrm{s}\end{array}$} & \multirow{2}{*}{$\begin{array}{c}\text { Active, partial } \\
\text { compensation } \\
\text { at } 55 \mathrm{~m} / \mathrm{s}\end{array}$} \\
\hline & $50 \mathrm{~m} / \mathrm{s}$ & $55 \mathrm{~m} / \mathrm{s}$ & & & \\
\hline $\begin{array}{l}\text { Test 1a: short-transition } \\
\text { running on }(\%)\end{array}$ & 44.8 & 65.9 & 51.9 & 49.8 & 52.7 \\
\hline $\begin{array}{l}\text { Test } 1 \mathrm{~b} \text { : short-transition } \\
\text { running off }(\%)\end{array}$ & 44.3 & 61.3 & 42.3 & 41.4 & 45.9 \\
\hline Test 2 : reverse curve $(\%)$ & 44.5 & 65.9 & 54.8 & 53.1 & 52.2 \\
\hline $\begin{array}{l}\text { Test 3a: normal-transition } \\
\text { running on }(\%)\end{array}$ & 32.7 & 45.4 & 33.0 & 32.6 & 35.4 \\
\hline $\begin{array}{l}\text { Test } 3 \mathrm{~b} \text { : normal-transition } \\
\text { running off }(\%)\end{array}$ & 31.6 & 43.1 & 26.5 & 26.9 & 31.0 \\
\hline $\begin{array}{l}\text { Test } 5 \text { : straight-line track } \\
\text { performance }(\mathrm{mg})\end{array}$ & 26.6 & 26.6 & 28.6 & 28.6 & 28.6 \\
\hline
\end{tabular}

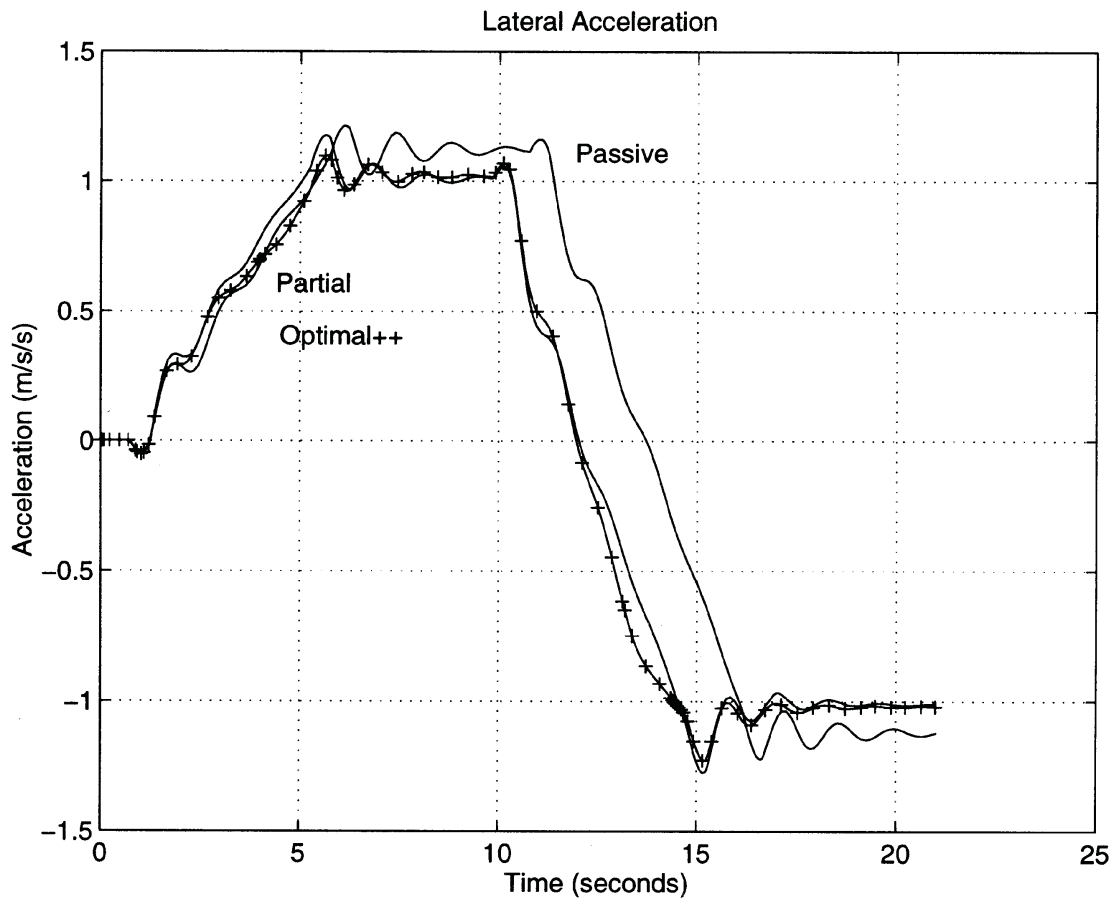

Fig. 11 Lateral acceleration

shows the secondary suspension roll rate, Fig. 15 shows the actuator power and Fig. 16 shows the actuator torque levels.

\subsection{Full vehicle model results}

The classical control laws were then transferred to the full vehicle model. Initially the symmetric strategy controlling the actuators to the same length was used to implement the full and partial compensation control laws, enabling a comparison with the end-view results to be made. Table 4 shows the performance of the various control laws for the different test conditions.

An important consideration for the operation of the complete vehicle control systems is that they should not make the wheel off-loading exceed allowable limits. This can be achieved either by controlling the lengths of the two linear actuators so that they do not differ by more than $10 \mathrm{~mm}$ or by controlling the forces generated by the two linear actuators so that they do not differ by more than $3.6 \mathrm{kN}$. These specifications were based on the following assumptions: in-board bearing bogie with a torsionally 'flexible' frame; $39 \mathrm{t}$ vehicle weight on rail; $2.5 \mathrm{MN} / \mathrm{m}$ stiffness of anti-roll bar; $1.65 \mathrm{~m}$ lateral spacing between vertical roll bar links. Only the master/slave and symmetric control options can be configured to perform this function, and such a configuration is termed an integrated tilt control system.

The independent control system has the potential for the two active anti-roll bars to apply opposing torques on cant gradients. This would twist the body and could result in wheel off-loading and even derailment. 


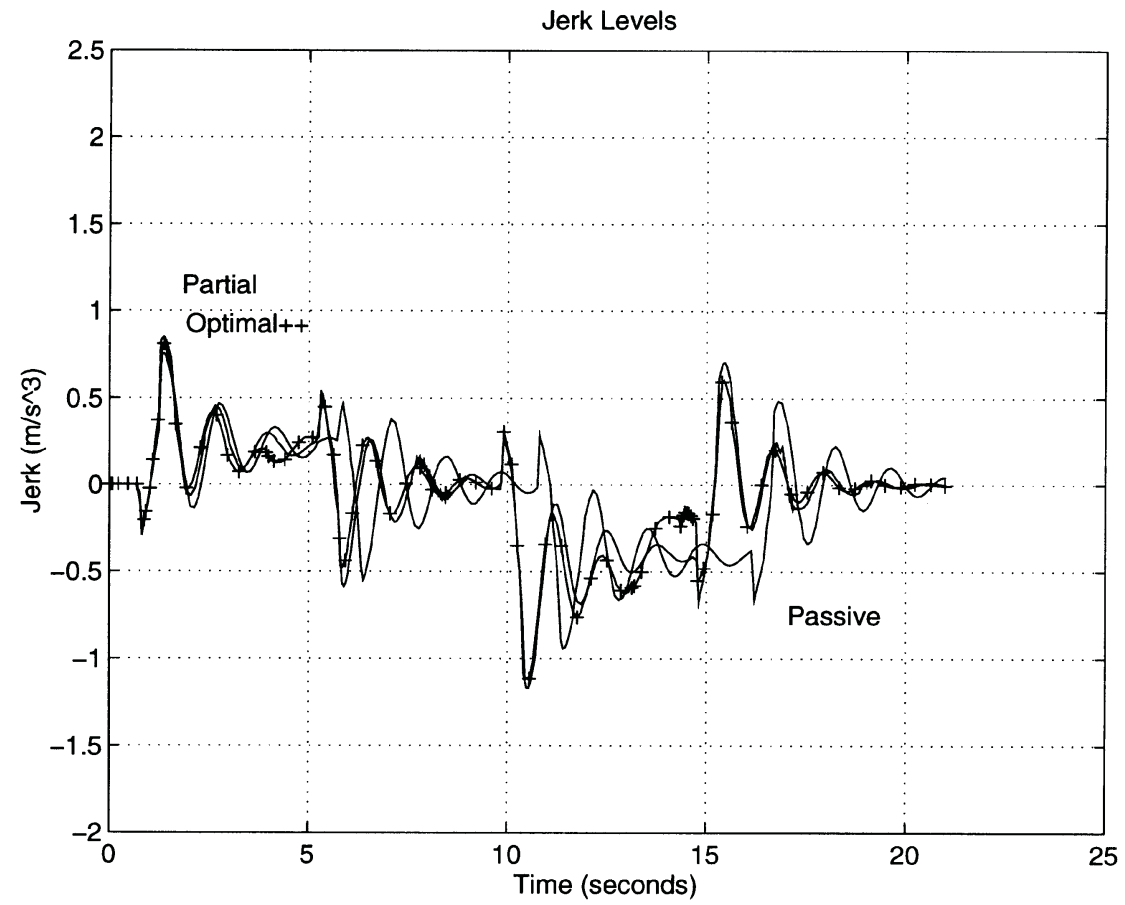

Fig. 12 Body jerk levels

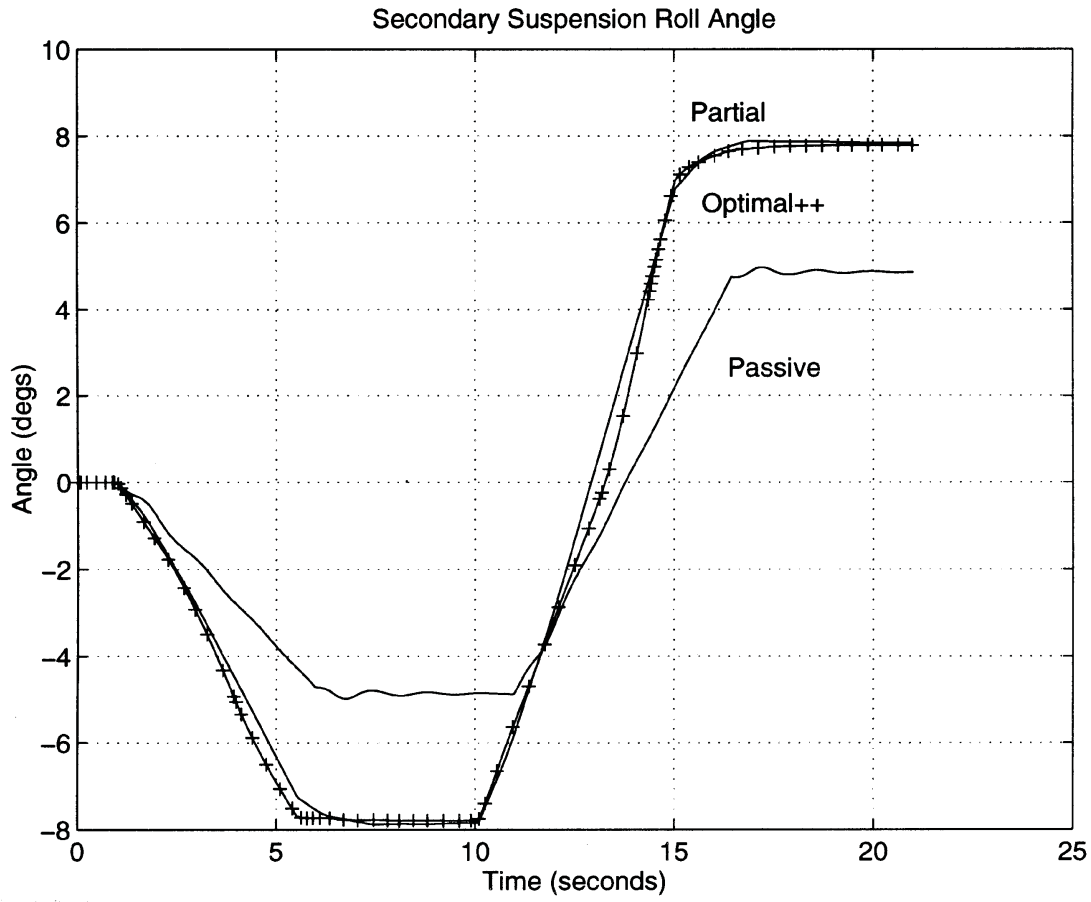

Fig. 13 Body roll angle

Controlling the actuators to the same length ( \pm tolerance) ensures that the wheel off-loading case is no worse than the passive suspension. Controlling the actuators to provide the same torque eliminates the twist on the body and improves the wheel off-loading specification over the passive suspension, although failures must be accommodated.
In order to maintain equal actuator torques (or forces) a 'torque correction' signal needs to be applied to one of the actuators. Since the actuator torque, $T$, is proportional to the secondary suspension roll angle, $\phi_{\mathrm{r}}$, and to the actuator input, $\phi_{\mathrm{a}}$, the following equations can be derived for the roll bar torques: 


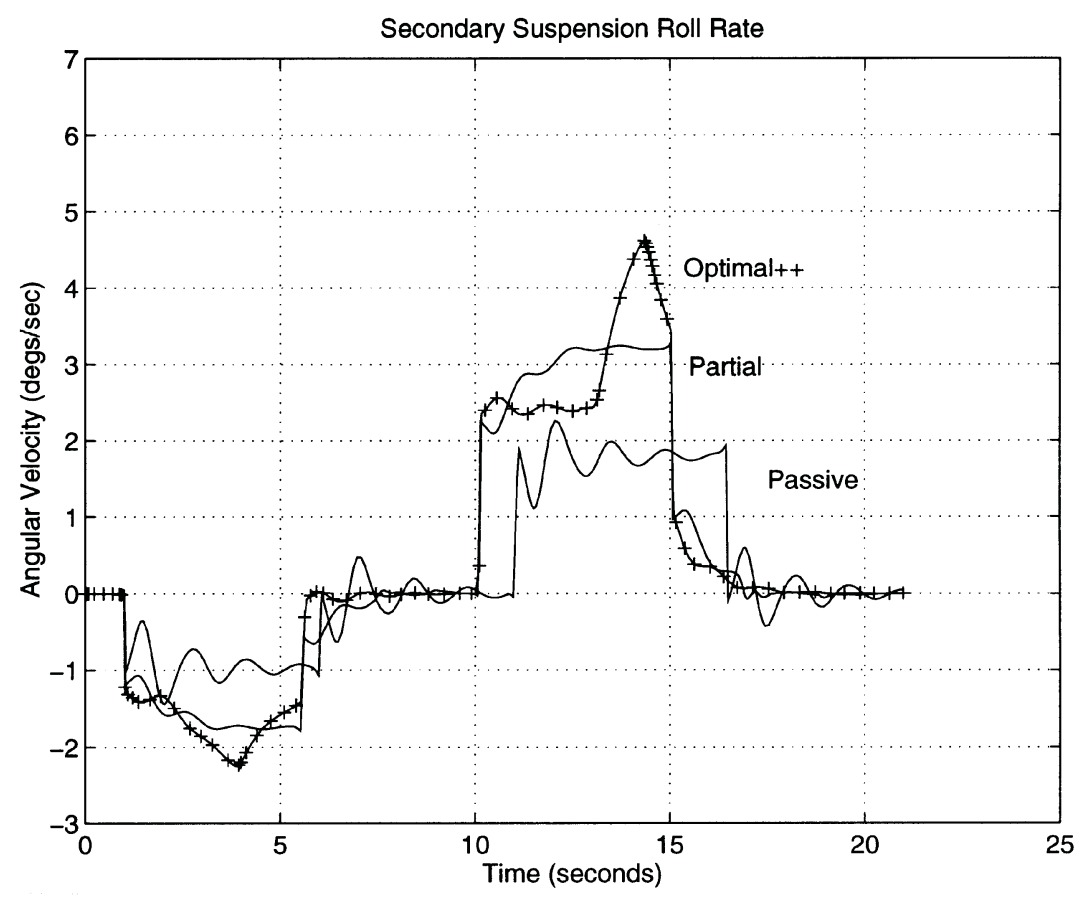

Fig. 14 Body roll rate

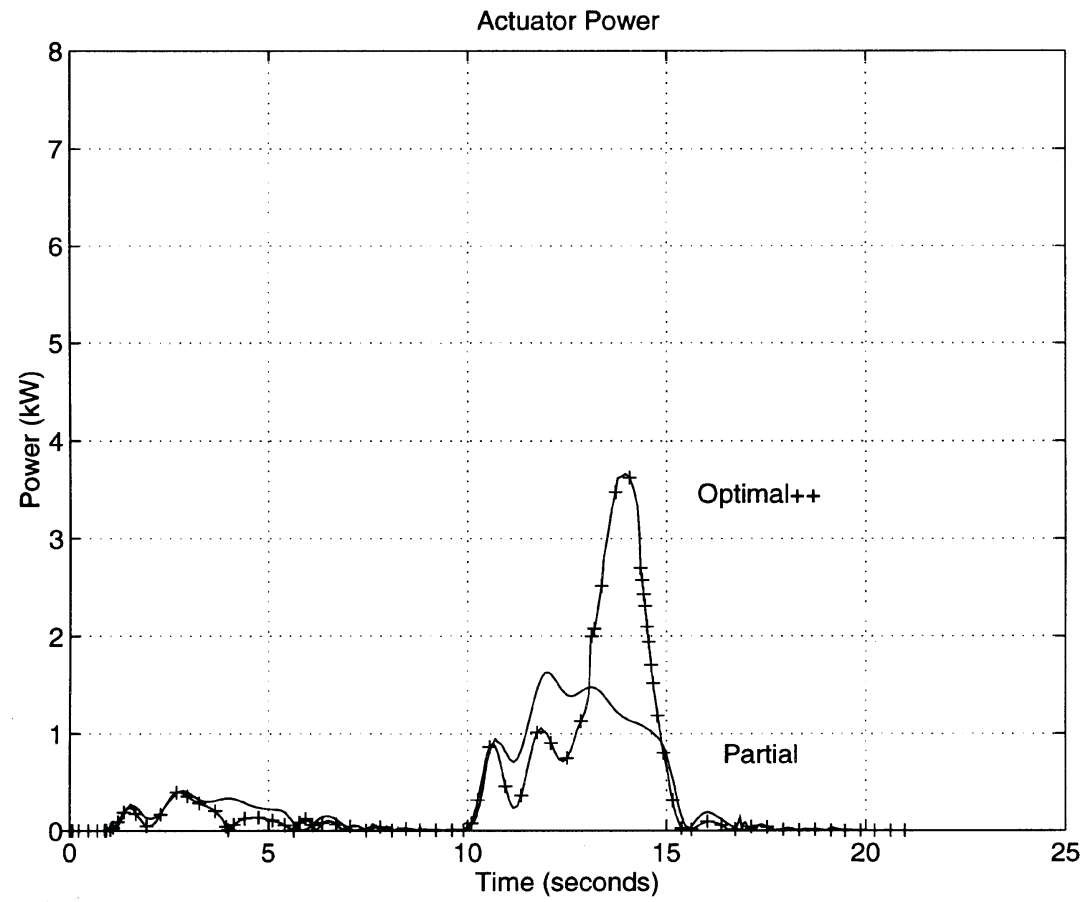

Fig. 15 Actuator power

$$
\begin{aligned}
& T_{1}=K_{\mathrm{a}}\left(\phi_{\mathrm{r} 1}-\phi_{\mathrm{a} 1}\right) \\
& T_{2}=K_{\mathrm{a}}\left(\phi_{\mathrm{r} 2}-\phi_{\mathrm{a} 2}\right)
\end{aligned}
$$

and therefore the drive signal for the second actuator is

$$
\left.\phi_{\mathrm{a} 2}\right|_{T_{1}=T_{2}}=\phi_{\mathrm{a} 1}-\left(\phi_{\mathrm{r} 1}-\phi_{\mathrm{r} 2}\right)
$$

There are some differences between these results and the results from Table 3, which are attributed to the implementation differences between the end-view controller and the plan-view controller(s), i.e. the leading roll bar does not get a true signal and is driven by an averaged signal in a similar manner to the trailing roll bar, thus leading to a slight degradation in results.

Table 5 shows the performance of the classical full 


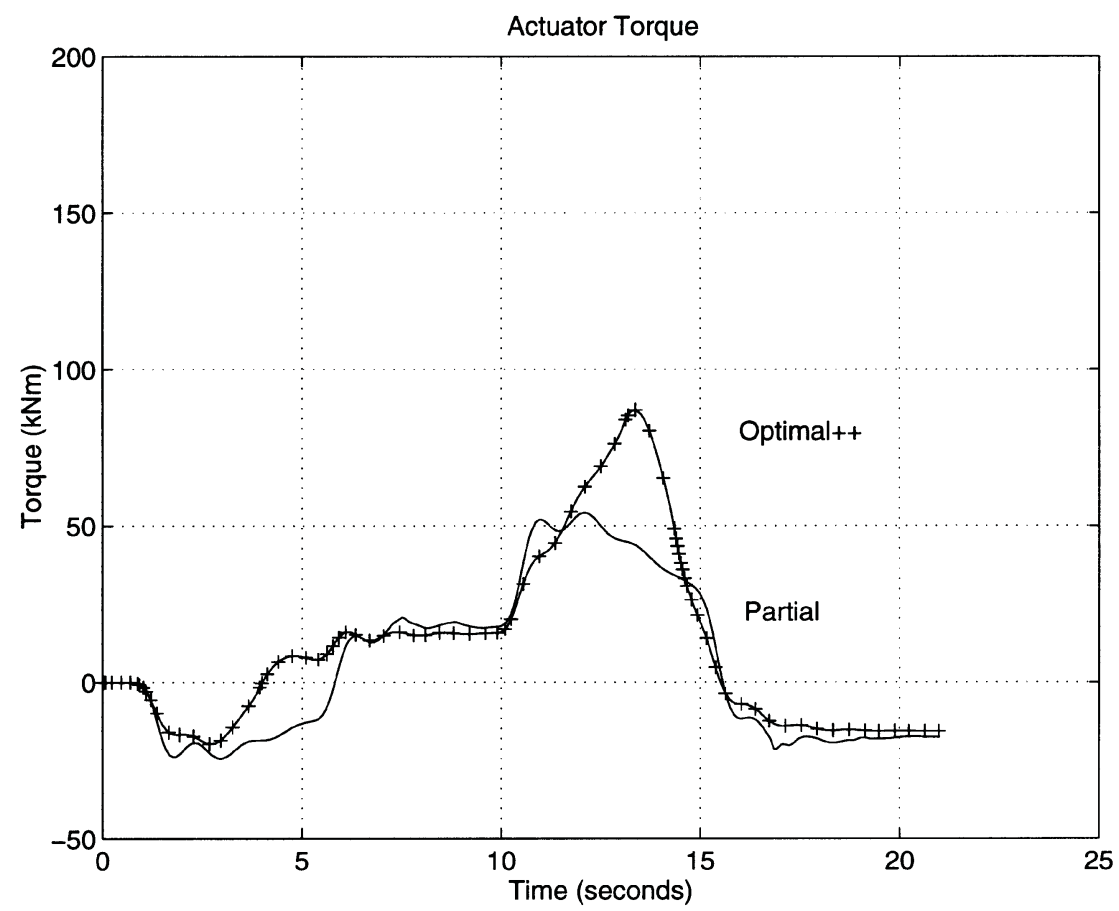

Fig. 16 Actuator torque levels

Table 4 Performance of passive and active anti-roll bars (plan-view model)

\begin{tabular}{ccccc}
\hline \multirow{2}{*}{$\begin{array}{c}\text { Tilt strategy } \\
\text { performance }\end{array}$} & $50 \mathrm{~m} / \mathrm{s}$ & $55 \mathrm{~m} / \mathrm{s}$ & $\begin{array}{c}\text { Active, full } \\
\text { compensation } \\
\text { at } 55 \mathrm{~m} / \mathrm{s}\end{array}$ & $\begin{array}{c}\text { Active, partial } \\
\text { compensation } \\
\text { at } 55 \mathrm{~m} / \mathrm{s}\end{array}$ \\
\cline { 2 - 5 } & 47.0 & 66.9 & 53.4 & 54.3 \\
$\begin{array}{c}\text { Test 1a: short-transition } \\
\text { running on (\%) }\end{array}$ & 40.3 & 66.5 & 50.0 & 56.9 \\
$\begin{array}{c}\text { Test 1b: short-transition } \\
\text { running off (\%) }\end{array}$ & 40.7 & 62.2 & 53.9 & 56.5 \\
$\begin{array}{c}\text { Test 2: reverse curve (\%) } \\
\text { Test 3a: normal-transition } \\
\text { running on (\%) }\end{array}$ & 29.6 & 41.4 & 31.1 & 31.7 \\
$\begin{array}{c}\text { Test 3b: normal-transition } \\
\text { running off (\%) }\end{array}$ & 27.8 & 42.3 & 32.6 & 33.1 \\
$\begin{array}{c}\text { Test 5: straight-line track } \\
\text { performance (mg) }\end{array}$ & 20.1 & 20.1 & 20.7 & 20.9 \\
\hline
\end{tabular}

Note. Acceleration is taken to be the average of the acceleration measured at the body centre of gravity, at the leading bogie pivot and at the trailing bogie pivot.

Table 5 Performance of active anti-roll bar full vehicle strategies (classical full compensation control strategy)

\begin{tabular}{llc}
\hline \multicolumn{1}{c}{ Plan-view strategy } & \multicolumn{1}{c}{$\begin{array}{c}\text { Comfort on curve, } \\
\text { test 1a at } 55 \mathrm{~m} / \mathrm{s} \\
(\%)\end{array}$} & $\begin{array}{c}\text { Straight-track } \\
\text { performance at } \\
55 \mathrm{~m} / \mathrm{s} \\
(\mathrm{mg})\end{array}$ \\
\hline Passive & $47.0($ at $50 \mathrm{~m} / \mathrm{s})$ & 20.1 \\
Independent & 54.8 & 20.5 \\
Master/slave (with torque feedback) & 52.7 & 21.3 \\
Master/slave (with length feedback) & 52.1 & 21.3 \\
Symmetric (with torque feedback) & 53.1 & 20.7 \\
Symmetric (with length feedback) & 53.4 & 20.7 \\
\hline
\end{tabular}

F00697 (C) IMechE 1998 compensation tilt control law when implemented as independent, symmetric or master/slave vehicle tilt control strategies. There was little difference in the performance of the plan-view strategies, except for the independent strategy, which failed the wheel off-loading criterion (this was assessed separately as a check for each strategy, although the details have not been included here). There was also a marginal difference in the actuator requirements, although the variation was small (approximately 10 per cent). The results are shown in Table 6. It should be noted that the performance of the master/slave tilt control strategy would be worse if the vehicle were run backwards. In its 
Table 6 Actuator requirements of active anti-roll bar full vehicle strategies (classical full compensation control strategy)

\begin{tabular}{lccc}
\hline \multicolumn{1}{c}{ Plan-view strategy } & $\begin{array}{c}\text { Comfort on curve, } \\
\text { test 1a at 55 m/s }\end{array}$ & $\begin{array}{c}\text { Peak actuator force } \\
\text { requirement }(\mathrm{kN})\end{array}$ & $\begin{array}{c}\text { R.m.s. actuator force } \\
\text { requirement }(\mathrm{kN})\end{array}$ \\
\hline Independent & 54.8 & 3.66 & 1.427 \\
Master/slave (with torque feedback) & 52.7 & 3.61 & 1.400 \\
Master/slave (with length feedback) & 52.1 & 3.86 & 1.398 \\
Symmetric (with torque feedback) & 53.1 & 3.42 & 1.390 \\
Symmetric (with length feedback) & 53.4 & 3.41 & 1.388 \\
\hline
\end{tabular}

correct configuration the trailing roll bar effectively benefits from full vehicle preview.

\subsection{Actuator specifications}

The actuator specifications were calculated using results from the performance of the strategies on test track 1a at $55 \mathrm{~m} / \mathrm{s}$ and are summarized in Table 7 .

\section{DISCUSSION}

The main advantages of the classical partial compensation strategy are lower peak actuator power requirements, reduced roll rates and reduced jerk levels. The main disadvantage of this strategy is that at reduced speeds the full allowable tilt may not be used.

The main advantages of the classical full compensation strategy are that it has a quick response and that it uses the maximum allowable tilt whenever possible. Its main disadvantages are that, owing to its responsiveness, it produces high roll rates and high jerk levels (also due to controller switching). Furthermore, because of the high roll rates the peak actuator power requirements are high. Many of these disadvantages have been overcome by moving the tilt limits in relation to the filter in order to provide a smoother switching curve. These advantages and disadvantages are summarized in Table 8 .

With the classical control strategies there is a small steady-state error due to proportional action, which can be eliminated using an integral action. This may lead to marginal improvements in performance, but it does complicate the tuning process.

Table 7 Actuator specifications (test track $1 \mathrm{a}$ at $55 \mathrm{~m} / \mathrm{s}$ )

\begin{tabular}{lccc}
\hline & $\begin{array}{c}\text { Full } \\
\text { compensation }\end{array}$ & $\begin{array}{c}\text { Partial } \\
\text { compensation }\end{array}$ & $\begin{array}{c}\text { Optimal } \\
\text { control }\end{array}$ \\
\hline $\begin{array}{l}\text { Maximum velocity } \\
\text { rad/s }\end{array}$ & 0.032 & 0.031 & 0.037 \\
$\quad$ m/s & 0.064 & 0.061 & 0.073 \\
R.m.s. velocity & & & \\
$\quad$ rad/s & 0.013 & 0.013 & 0.014 \\
m/s & 0.025 & 0.026 & 0.027 \\
Maximum torque $(\mathrm{kN} \mathrm{m})$ & 34.29 & 36.43 & 29.75 \\
R.m.s. torque $(\mathrm{kN} \mathrm{m})$ & 20.35 & 20.47 & 16.02 \\
Maximum force $(\mathrm{kN})$ & 17.15 & 18.21 & 14.88 \\
R.m.s. force $(\mathrm{kN})$ & 10.17 & 10.23 & 8.01 \\
\hline
\end{tabular}

Proc Instn Mech Engrs Vol 212 Part F
Table 8 Comparison of full and partial compensation control strategies

\begin{tabular}{|c|c|c|}
\hline & Full compensation & Partial compensation \\
\hline Advantages & $\begin{array}{l}\text { Quick response; provides } \\
\text { full compensation on } \\
\text { curves at low speeds, } \\
\text { making best use of } \\
\text { allowable tilt }\end{array}$ & $\begin{array}{l}\text { Low peak actuator power } \\
\text { requirements; low jerk } \\
\text { levels and roll rates }\end{array}$ \\
\hline Disadvantages & $\begin{array}{l}\text { High jerk levels and roll } \\
\text { rates; high peak } \\
\text { actuator power } \\
\text { requirements }\end{array}$ & $\begin{array}{l}\text { On curves at low speeds } \\
\text { this strategy does not } \\
\text { make use of allowable } \\
\text { tilt }\end{array}$ \\
\hline
\end{tabular}

The optimal control strategy poses a number of problems in the formulation of the model. It also requires the feedback of a large number of variables, some of which may not be measurable and will therefore need to be estimated. However, the preliminary results have shown that good performance can be achieved with this strategy, although, given the need to provide state estimation, the robustness to variations in the system parameters needs careful assessment. The results presented in this paper for the optimal strategy are for the end-view model. To implement the strategy on the plan-view model there are a number of issues that must be addressed. It may be possible to implement two independent controllers, but, as with the classical strategies, this may lead to unacceptable wheel off-loading conditions. A symmetric strategy may not be appropriate, since this averages the signals from sensors at each end of the vehicle, and for the optimal control approach this may lead to instability. One solution may be to use a more comprehensive controller design model that includes some of the full vehicle dynamics as well as the end-view dynamics, in which case it may be possible to include the wheel off-loading criterion in the performance index as well, but there will be implementation difficulties due to the high order of the state estimators.

\section{CONCLUSION}

The results show that all control strategies provide good tilt control performance and appear suitable for further study and experimental assessment. The optimal control strategy performs slightly better than the classical control 
approaches. However, it may be possible to improve the performance of the classical control strategies to equal that of the optimal control strategy by using extra feedback loops so that both strategies feed back the same variables.

The fundamental trade-off is between curving and straight-track performance: good curving performance can be achieved, but at the expense of straight-track performance. This trade-off may be eased by the use of a lateral actuator in the secondary suspension, i.e. it may be necessary to have some form of active lateral suspension combined with the active anti-roll bar to obtain the benefit of higher speeds on curves. Careful controller design will be required with respect to the cross-coupling of these modes. Assuming that the cost function can be correctly formulated, the optimal control approach provides a natural optimization method for controlling both of these control channels, taking into account the dynamic interaction.

In summary, the potential advantage of active tilting vehicles depends on achieving acceptable ride quality while traversing curves at speeds above the limits set by the ride comfort requirements for non-tilting vehicles, and at the same time not significantly degrading the straight-line performance.

\section{ACKNOWLEDGEMENTS}

The work presented in this paper is from a research project in collaboration with Bombardier Pro-Rail Limited and Lamerholm-Fleming Limited and funded by the Department of Trade and Industry.

\section{REFERENCES}

1 Losa, P. The Pendolino body tilt control. Energia Elettrica, 1987, 64(1), 33-44.

2 Losa, P. and Elia, P. The System Fiat Pendolino: design characteristics, service, tests, developments. In Proceedings of International Conference STech 93, Yokohama, 1993, Vol. 2, pp. $5-10$.

3 Andersson, E. and Nilstan, N. The development of advanced high-speed vehicles in Sweden. Proc. Instn Mech. Engrs, Part D, 1984, 198(D15), 229-237.

4 Alexandersson, A. and Edwards, T. The Swedish X2000 tilting high-speed train. In Proceedings of International Conference STech 93, Yokohama, 1993, Vol. 2, pp. 11-16.

5 Sasaki, K., et al. Active tilting control of series E991 EMU experimental train (development of third generation of active tilting control). In Proceedings of IMechE Conference STech 96, 1996, paper C514/055/96.

6 Nakagawa, A. The latest pendulum EMU train (series 383). Jap. Railway Engng, 1995, 135.

7 Marshall, J. J. and Halfpenny, D. Tilt technology. General lecture presented to Railway Division of IMechE, London, 1977.

8 Kurokawa, Y., et al. Limited-angle tilt control system by air springs. In Proceedings of International Conference STech 93, Yokohama, 1993, Vol. 2, pp. 361-364.

9 Dusing, M., et al. Wankstutze für Schienenfahrzeuge. German Pat. DE4311521C1, April 1994.

10 Sharp, R. S. and Pan, D. On the design of an active roll control system for a luxury car. Proc. Instn Mech. Engrs, Part D, Journal of Automobile Engineering, 1993, 207(D4), 275-284.

11 Railway applications ride comfort for passenger measurements and evaluation. DK CEN TC/256 Working Group 7, 4th Draft Report Rev. (9.9.1993).

12 Boocock, D. and Newman, M. The advanced passenger train. Railway Division of IMechE, London, 1976.

\section{APPENDIX}

Curve transition test cases $(C=$ cant, $L=$ transition length, $R=$ radius $)$

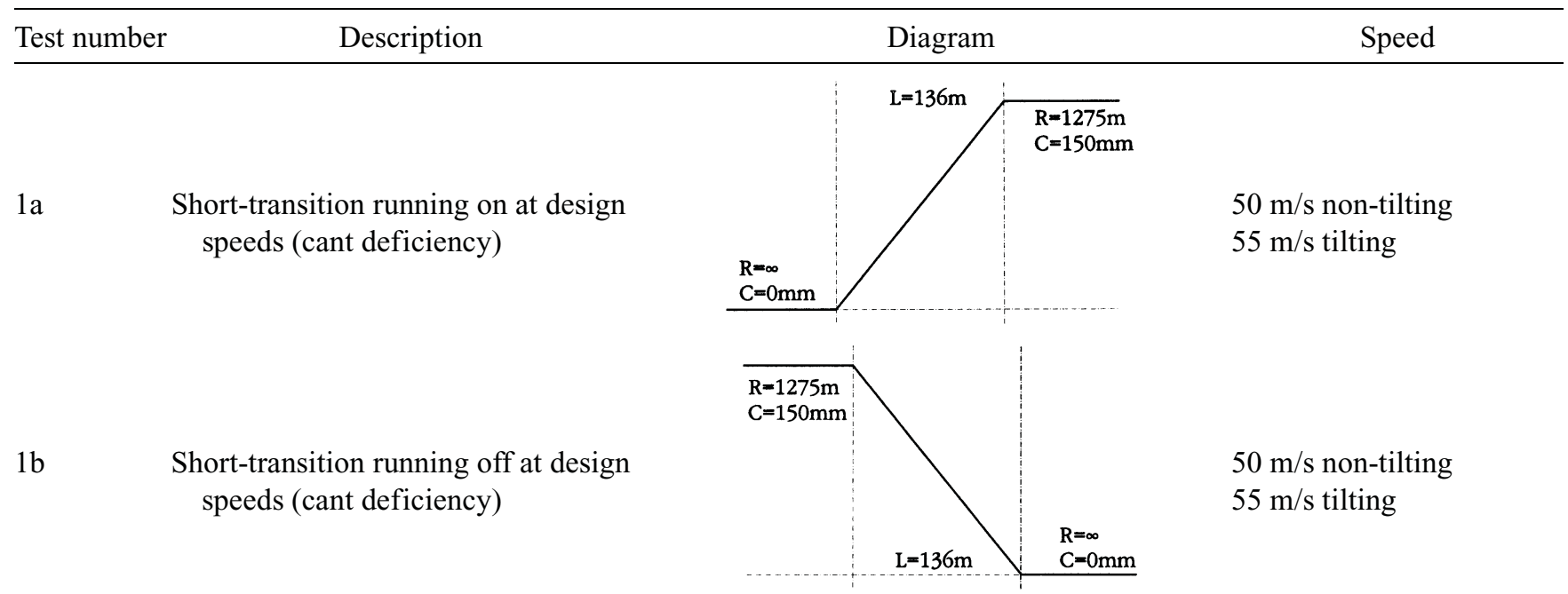




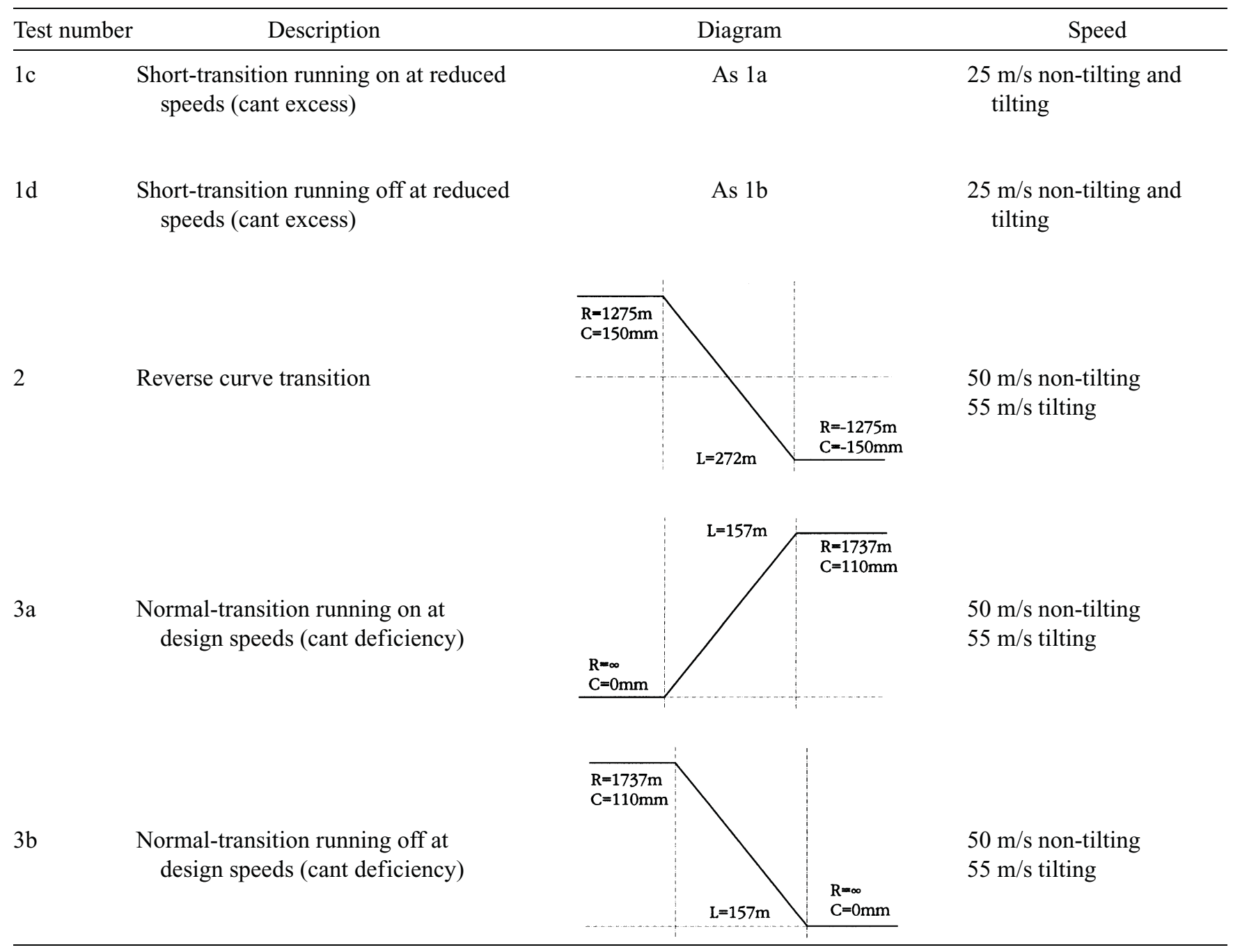

